\title{
WestVirginiaUniversity
}

THE RESEARCH REPOSITORY @ WVU

Graduate Theses, Dissertations, and Problem Reports

2020

\section{Regional Variation on Loanword Adaptation in Japanese}

\author{
Yuki Hattori \\ yh0020@mix.wvu.edu
}

Follow this and additional works at: https://researchrepository.wvu.edu/etd

Part of the Modern Languages Commons, and the Other Languages, Societies, and Cultures

Commons

\section{Recommended Citation}

Hattori, Yuki, "Regional Variation on Loanword Adaptation in Japanese" (2020). Graduate Theses, Dissertations, and Problem Reports. 7583.

https://researchrepository.wvu.edu/etd/7583

This Thesis is protected by copyright and/or related rights. It has been brought to you by the The Research Repository @ WVU with permission from the rights-holder(s). You are free to use this Thesis in any way that is permitted by the copyright and related rights legislation that applies to your use. For other uses you must obtain permission from the rights-holder(s) directly, unless additional rights are indicated by a Creative Commons license in the record and/ or on the work itself. This Thesis has been accepted for inclusion in WVU Graduate Theses, Dissertations, and Problem Reports collection by an authorized administrator of The Research Repository @ WVU. For more information, please contact researchrepository@mail.wvu.edu. 
Regional Variation on Loanword Adaptation in Japanese

Yuki Hattori

Thesis submitted

To the Eberly College of Arts and Sciences

at West Virginia University

in partial fulfillment of the requirements for the degree of

Master of Arts in World Languages, Literatures, and Linguistics (Linguistics)

Department of World Languages, Literatures, and Linguistics

\author{
Sergio Robles-Puente, Ph.D., Chair \\ Sandra Stjepanovic, Ph.D. \\ Jonah Katz, Ph.D.
}

Department of World Languages, Literatures, and Linguistics

Morgantown, West Virginia

2020

Keywords: Japanese loanwords, loanword abbreviations, truncations, Japanese phonology, Japanese sociolinguistics, prosodic features Copyright 2020 Yuki Hattori 


\author{
Abstract \\ Regional Variation on Loanword Adaptation in Japanese
}

\begin{abstract}
Yuki Hattori
This thesis examines the variations of loanword abbreviations in Japanese dialects. When adopting foreign words into Japanese, phonological grammar is applied creating loanwords. When loanwords are introduced, Japanese phonological rules determine how to pronounce the new words; Japanese truncation styles are applied to shorten and abbreviate loanwords. Much like native Japanese words, regional variations can be observed in loanword abbreviations. In order to discover how variations are created, this study compares two dialects: the eastern Japanese dialect (standard dialect) and the western Japanese dialect (Kansai dialect). Despite a recent decrease in popularity, the Kansai dialect is still one of the most prestigious dialects in Japan. This thesis addresses and explores how variations between two regions, Nagoya (east) and Kansai (west) are generated. A survey was conducted with the help of 121 university students from both regions. The methods used were a perception test, an acceptability judgement test, a production test, and an additional questionnaire. The data analysis reveals that adaptations in loanword abbreviations are closely related to Japanese sociophonetics and phonology. Results further show how cultural histories impact the modern Japanese lexico
\end{abstract}




\section{Acknowledgements}

I wish to send my sincerest gratitude to my thesis chair, Sergio Robles-Puente, Ph.D. and thesis committee members, Sandra Stjepanovic, Ph.D. and Jonah Katz, Ph.D. Thank you for your patience and guidance. I would also like to thank West Virginia University for allowing me to study abroad in this beautiful country.

Finally, I want to thank my family back home in Japan. Thank you for believing in me. 


\section{Table of Contents}

1 Introduction__ 1

1.1 Japanese as a Mora-Based Language __ 3

1.2 Pitch Accents in Japanese Dialects ___ 5

1.2-1. Kansai-Ben

1.2-2 Nagoya Dialect —_ 8

1.3 Loanwords __ 9

1.3-1 Adaptation of loanwords

$1.3-2$ Accents _ 12

1.3-3 Abbreviation — 13

1.4 History of Japanese Language __ 16

1.4-1 Japanese Lexicon___ 16

1.4-2 Language Evolution__ 16

1.4-3 Wakamono Kotoba__ 18

1.4-4 History of Kansai Dialect __ 19

2 Methodology 21

2.1 Subjects __ 21

2.2 Experiments _ 21

2.2-1 Perception Test — 21

2.2-2 Acceptability Judgement Test _ 23

2.2-3 Production Test

2.2-4 Additional Questions __ 24

3 Results 24

3-1. Perception___ 24

3.2 Acceptability ___ 26

3.3 Production _ 29

3-3.1 Accents for Three-mora Words _ 30

3-3.2 Accents for Four-mora Words _ 30

3-3.3 Compound words _ 32

3-3.4 Three or Four-mora? _ 34

3.4 Additional Questions ___ 37

3.4-1. The Differences between East and West___ 37

3.4-2. Where Do They Learn Abbreviations? 38

3.4-3. Why do you think the abbreviations are convenient? 38

4 Discussion — 39

5 Conclusion__ 42

Bibliography_ 45

Appendix__ 48

1. Productions from East and West __ 48

2. Additional Questionnaire _ 55 


\section{Introduction}

In the Japanese language, a large number of loanwords from different languages can be found. Many loanwords are pronounced differently from the original words by applying Japanese phonological features, and some of the words are shortened by the speakers. Most of these adaptations are likely to originate from younger generations. According to the National Institute for Japanese Language and Linguistics (2002), more than 60\% of Japanese speakers over the age of sixty hardly know about loanwords and abbreviation. Japanese people have a special term for these lexicons that young people use: Wakamono Kotoba. Besides Wakamono Kotoba, it seems that dialectal variation is a cause of variation observed in certain loanwords. Japanese is known for having two main types of dialects in the mainland: eastern-type and western-type. The western-type dialect is spoken mainly in the Kansai area is fittingly called "Kansai dialect" or "Kansai-Ben." On the other hand, the eastern type is called "Tokyo speech" (Figure 1).

Figure 1. Map of Japan

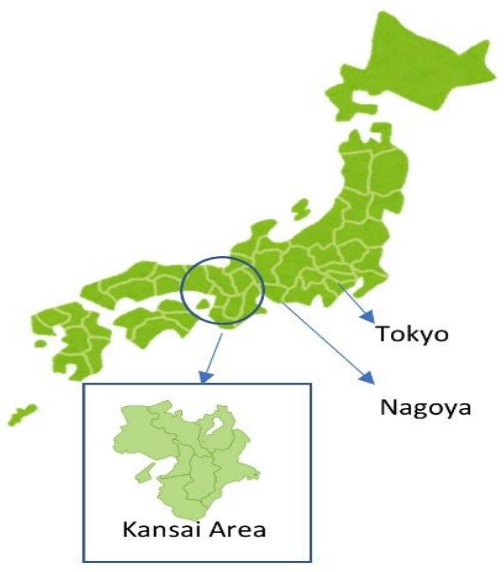

According to Maynard (2011), the differences between the two dialects are significant, and generally found in people's vocabulary, word formations and tonal systems. Okayama University 
of Science professor Fudano Kazuo ${ }^{1}$, a specialist in dialectology, argues that Kansai-ben speakers pronounce vowels stronger and clearer than Tokyo speakers. For instance, the phrase 'thank you' in Japanese is [arigato:gozaimasu]. There are differences in the location and realization of pitch accents in the two varieties (Kansai and Tokyo). In Tokyo-speech, it is likely to hear rising pitches on /ri/ and /za/ syllables, a high plateau for the following syllables, and the last vowel /u/ is usually devoiced. In Kansai-ben, however, there tends to be rising pitches on /o:/ and /w/ instead. Horio (2015), suggests that not only native Japanese words but also new expressions coined by younger speakers vary from region to region. There are several loanwords that are pronounced and clipped differently among young people depending on the dialect they speak. For instance, young people that live on the east side of $\mathrm{Japan}^{2}$, abbreviate the loanword /makudonarudo/ (McDonald's) [makku]. People who live on the west side of Japan, such as Osaka residents, call McDonald's [makudo], with a rising pitch on $/ \mathrm{kw} /$. This is one of the most well-known examples that show in loanword abbreviations between the east and the west. According to Kibe (2019), those abbreviations from both areas contrast not only in the number of syllables but also in the use of rising pitch. The western dialect differs from standard Japanese in the use of rising pitch. Not only does this rule apply to loanwords, but it also applies to modern Japanese words. Kibe (2019) also explains that Japanese dialects do not provide the information of word recognitions but provide the speaker's dialectal background. For instance, the word 'bridge' is [hafI] in Japanese. The western dialect speakers put a rising pitch accent on /a/. Alternatively, for the eastern Japanese speakers [ha/I] with the rising pitch on /a/ means 'chopsticks.' For saying 'bridge', the eastern people are likely to put a rising pitch on $/ \int \mathrm{I} /$, which means 'chopsticks' for the western speakers. Maynard (1997) agrees with Fudano (2019) and

\footnotetext{
${ }^{1}$ Fudano (2019)- these were personal communications that took place at Kansai Foreign Language University.

${ }^{2}$ In this study, the city of Nagoya is used to represent the East area dialect. You can also see Figure1.
} 
states that words are pronounced differently depending on the regions. Kansai speakers tend to have a distinct rising pitch more than Tokyo speakers do. A good representation of this contrast are the cities of Nagoya and Tokyo. Yoshida (2017) claims that Nagoya dialect favors the rising pitch at the end of the word (p.43). When examining these observations, it is imperative to understand how differences between the dialects can be made. This study, therefore, observes prosodic features of Japanese dialects with the emphasis on loanword abbreviations. Japanese has several different phonological characteristics not found in English. The following sections will address the main features of Japanese phonology and will explain the dialectal contrast in more detail.

\subsection{Japanese as a Mora-Based Language}

According to Otake (2015), "the mora is a phonological unit" (p. 493) and composed by two types of syllables: light and heavy. Typically, Japanese syllables follow the ' $\mathrm{CV}$ ' pattern formed by a light ' $C$ ' and a ' $V^{\prime 3}$ (i.e. light syllable). Grenon (2015) mentions that each syllable must be a combination of a consonant and a vowel. Although, there are sounds do not follow the CV pattern, such as a coda nasal /N/, a long vowel /:/, a geminate consonant /:/, and vowels /a, i, u, e, o/. Grenon (2015) mentions; for instance, the noun 'book' is [hoN] in Japanese has two moras and one syllable. Words that include long vowels and geminations such as 'school' [gak:o:] are counted as a four-mora word. Table 1 shows loanword examples explaining how to count Japanese moras (Table 1).

${ }^{3}$ C: Consonant V: Vowel 
Table 1: Examples of Japanese mora in loanwords

\begin{tabular}{|c|c|c|}
\hline English & $\begin{array}{l}\text { Japanese (IPA and } \\
\text { orthography) }\end{array}$ & The number of moras \\
\hline America & [amerika]（アメリカ） & 4 \\
\hline Bed & [bet:o]（ベット） & 3 \\
\hline Concert & [koNsa:to]（コンサート） & 5 \\
\hline Gray & [gure:]（グレー） & 3 \\
\hline
\end{tabular}

Table 1 indicates examples transcribed in the IPA and written in Japanese alphabets. As described in Table 1, one Japanese Katakana or Hiragana symbol is equal to one mora. Otake (2015) notes that Japanese native speakers sometimes refer to this unit as ' $h a k u$.' This haku is used for making Japanese traditional poetry, known as haiku. For native Japanese speakers, it is widely known that each letter is counted as one mora (or $h a k u$ ) in order to compose traditional Japanese poems. Otake, Hatano, Cutler, and Mehler (1993) indicate that moras do not have to correspond with syllables. The mora in Japanese is a subsyllabic unit. Therefore, "the mora can be thought of properly as a rhythmic unit" (p.258-260). As mentioned above, the word 'hon' has been described as having two moras even when it is monosyllabic. Otake, Hatano, Cutler, and Mehler (1993) also propose that "it is of particular interest that, given the restrictions on Japanese syllable structure, the consonants in a mid-word context, with the exception of the homorganic nasal, are always surrounded by two vocalist segments" (p. 260). This means that geminations cannot be located in the word-initial position or in the word-final position. However, the coda nasal /N/ can be located in the word-final position. ${ }^{4}$ Fudano (2019) mentions that western people tend to prefer three-mora words. He also indicates that this phenomenon comes from the fact that Kansai dialect has a special feature regarding a rising pitch. For

\footnotetext{
${ }^{4}$ The example of [hoN] on page 7.
} 
instance, Kansai speakers tend to put a rising pitch on the middle of the word. This feature applies not only to original Japanese words, but also to loanwords since source words sound unfamiliar to speakers. Having the knowledge of mora helps to understand the truncation and the pitch accent patterns in Japanese. Since truncation styles and a rising pitch differ from region to region, those topics should be taken into account for loanword abbreviations of Japanese. The next section will discuss pitch accents from each region.

\subsection{Pitch Accents in Japanese Dialects}

As mentioned before, Japanese words have rising pitches. These rising pitches are called pitch accent. Unlike English, which is syllable-based language, Japanese does not utilize stresses because the mora is singled out as a more distinctive unit than English syllables.

\section{2-1. Kansai-Ben}

In terms of pitch accent, Japanese is variable. Cutler and Otake (1999, p.1878) explain that "pitch accent in Japanese certainly provides information other than that relevant to word recognition." Therefore, Japanese speakers can use pitch accents to infer where other speakers are from. Ramsey (1979) indicates that Tokyo speech has both "unaccented" and accented words. "Unaccented" words, in this case, means that pitch accents in those words are unpredictable and are phonologically inert. However, accented words have a high pitch for accented sounds, and a low pitch for all succeeding syllables (p. 158). Warner (1997) also mentions that patterns for the latter feature in Tokyo speech are more limited than in Kansai-ben; for instance, Tokyo speech mostly has either HLL or LHL patterns (H=high, L=low). According to Warner (1997), a pitch should fall after accented mora (HL) unless there is a high pitch on the initial mora (LH). Kansai dialect, however, has more than these two types. Ramsey (1979) says 
"For in addition to a pitch fall, a low pitch on the first syllable is also distinctive" (p.158). He mentions that it also "has a pitch fall in the middle of the stem" (p. 160); for instance, LHL accents in [makúdo] from the English word "McDonald's." Kubozono (2012) also explains that Kansai- dialect is likely to place a pitch accent on the penultimate mora. Tokyo-speech, on the other hand, tends to put its pitch accent on the third syllable from the last one. Those differences are exemplified in (Table 2).

Table 2: Accent Pitch in Kansai and Tokyo-speech (Kubozono, 2012) ${ }^{5}$

\begin{tabular}{|l|l|l|}
\hline & Television & Hawaii \\
\hline Kansai & terebI & hawa \\
\hline Tokyo & terebı & hawa \\
\hline
\end{tabular}

Fudano (2019) also explains that Kansai speakers prefer three-mora words that have LHL pitch accentual patterns both in Native and Sino Japanese ${ }^{6}$ words. He adds to his claim: In order to have outside words sound familiar to their dialects, Kansai speakers adopt this accentual pattern in their loanwords, as well. Sanada (2018) mentions that this accentuation pattern is similar to the one found in four-mora words; (e.g. 'China' East: [t $\int$ úurgoku] West: [t $\int$ uuúgoku]). Cutler and Otake (1998) indicate that 4-mora words are likely to have a high pitch accent on the antepenultimate mora. When stressed syllables from source words contain geminated consonants, the accent moves one syllable to the left (p.1404). English word 'apple' is the example for this. Because this word has a geminated consonant and an antepenultimate mora in Japanese, /ap:uru/, the high pitch accent moves to the /a/ instead, [áp:uru].

\footnotetext{
${ }^{5}$ Bold type indicates the location of lexical accent.

${ }^{6}$ Sino Japanese is a type of Japanese lexicon which originally came from Chinese.
} 
Warner (1997) states that both Kansai dialect and Tokyo-speech have the same rule. In general, a mora before the accented mora has a low pitch, the accented mora has a high pitch, and the remaining moras after the accented moras have a low pitch (unless the word has its high pitch accent on the first mora). In addition to this, he found out that Tokyo listeners do not make distinctions between high-beginning (HL) and low-beginning words (LH). Whereas Osaka dialect listeners do distinguish the two accentual patterns. According to Warner (1997), both LHL and HLL accentual patterns can be found in both dialects, but Kansai-dialect also have more patterns that cannot be found in Tokyo speech, such as LLH as in [kandzi] 'Chinese character' (p.366). As mentioned above, other eastern dialects have less significant differences than between Tokyo speech and Kansai dialect. For instance, Nagoya dialect has slight differences from Tokyo speech regarding pitch accents as well. However, Yoshida (2017) and Kibe (2019) discuss that Nagoya speakers tend to use Tokyo speech rather than their own dialects, especially the younger generations. Not only do native Japanese words differ from region to region, but the high pitch accents of loanwords are different as well. Table 3 displays examples.

Table 3: The Adaptation Differences for Chain Stores in Japan between East and West

\begin{tabular}{|l|l|l|}
\hline Loanwords & $\begin{array}{l}\text { Eastern } \\
\text { (Tokyo/standard dialect) }\end{array}$ & Western (Kansai dialect) \\
\hline Macdonalds /maúudonaruido/ & {$[$ makkúu } & [makúdo] \\
\hline Family mart /famırı: ma:to/ & {$[$ fámıma] } & [famíma] \\
\hline Seven eleven /scbún Irébun/ & [sćbuun] & [scbúurı] \\
\hline
\end{tabular}




\section{2-2 Nagoya Dialect}

Yoshida (2017) observes differences in the pitch accents from Tokyo and Nagoya speakers. ${ }^{7}$ Table 4: Tokyo speech and Nagoya dialect pitch accent type

$\mathrm{L}=$ Low pitch $\mathrm{H}=\mathrm{High}$ pitch

\begin{tabular}{|l|l|l|}
\hline Original Words & Tokyo & Nagoya \\
\hline 'Cherry blossom' /sakura/ & LHH & LLH \\
\hline 'onion' /tamanegi/ & LHLL & LLHL \\
\hline 'eastern mountain' /higafijama/ & LHHHH & LLHHH \\
\hline
\end{tabular}

According to Yoshida (2017), the sudden rise of pitch is less distinctive in Tokyo speech than Nagoya dialect, but it is important to note that this applies to certain areas of the Tokai area where Nagoya dialect is spoken. Yoshida (2017) shows that those differences could not be seen anywhere in the Tokai area, meaning the neutralization has been happening in the Tokai area for a while. He also claims that Tokai speakers show a mixture of Tokyo and Nagoya type pitch (p.46). He concludes that there is no noticeable difference in pitch accents between Nagoya dialect and Tokyo speech (p.48). Likewise, Kibe (2019) precludes that Nagoya has a Tokyo-type accent although Nagoya is in-between Tokyo and Kansai geographically (p.94). This study will demonstrate the similarities and differences of these dialects with respect to prosodic features in loanword abbreviations.

Several differences can be observed within Nagoya and Tokyo dialects, although they do not have clear differences compared to Tokyo and Kansai or Nagoya and Kansai. This is because simplification and neutralization have been affecting Nagoya dialect. It is necessary to discuss

\footnotetext{
${ }^{7}$ Nine participants out of ten were born in between 60 s and 80 s, so the data might look different now.
} 
the loanwords because the differences and features in native Japanese can also be seen in the adaptation of loanwords.

\subsection{Loanwords}

\section{3-1 Adaptation of loanwords}

As mentioned before, Japanese does not allow to have sequenced consonants besides coda nasal /N/, gemination, and some specific alveolar sounds, such as /t $\mathrm{f} /$ and /ts/. Therefore, when adapting loanwords, a few special features are applied in order not to violate any Japanese phonological rules, and still retain part of the original word. For example, Kawahara (2015) mentions that many loanwords from English need either gemination or epenthesis. Japanese does not allow to have two consecutive consonants, such as /tw/ as in /twín/ in English. Therefore, epenthetic /u/ is inserted in order to follow Japanese phonotactic rules. Likewise, since Japanese does not have an alveolar stop sound /t/ as English does, /ts/ is used instead. Therefore, the word /twín/ is loaned as [tsuiN]. Another example Kawahara gives is the English word 'gray.' In order to follow Japanese phonotactics, the sequence /gr/ is produced as /gur/ and the diphthong /ei/ is produced as /e:/. Kawagoe (2015) also mentions that obstruents in the source words tend to undergo gemination in Japanese. In old Japanese, conjugations for adjectives and verbs were different from modern Japanese. By undergoing phonological changes as time passes, many conjugations tend to have CVCV clusters. For instance, the verb 'to cut' /kiru/, used to be conjugated [kirite]. This conjugation got changed to [kit:e] afterwards. There are several examples of changes in terms of conjugations (Table 4). 
Table 4: Sound Changes in Native Japanese Vocabulary ${ }^{8}$ (Kawagoe 2015)

\begin{tabular}{|c|c|c|}
\hline $\begin{array}{l}\text { Gemination: } \\
/ \mathrm{r} /, / \mathrm{w} /, / \mathrm{t} / \text {. }\end{array}$ & Dictionary Form & Past Tense \\
\hline 'to cut' & /kiru/ & [kit:a] \\
\hline 'to buy' & /kawul/ & [kat:a] \\
\hline 'to beat' & /untsu/ & [ut:a] \\
\hline $\begin{array}{l}\text { Coda Nasal: } \\
/ \mathrm{m} /, / \mathrm{n} /, / \mathrm{b} /\end{array}$ & & \\
\hline 'to read' & /jomu/ & [joNda] \\
\hline 'to die' & / jinu/ & [ $\mathrm{jiNda}]$ \\
\hline 'to fly' & /tobu/ & [toNda] \\
\hline $\begin{array}{l}\text { Deletion of } \\
\text { Consonants: /k/, /g/ }\end{array}$ & & \\
\hline 'to write' & /kaku// & [kaita] \\
\hline 'to swim' & /ojogu/ & [ojoida] \\
\hline
\end{tabular}

Chinese played an important role in the emergence of geminacy in Japanese. According to Kawagoe (2015), as briefly mentioned above, Japanese speakers perceive many loanwords as having geminated sounds despite the source words not having gemination. Just like the emergence of new consonants throughout the history, having many loanwords from Chinese was a crucial trigger for the emergence of geminacy. In Old Japanese, no geminated sounds existed. From 9th to 12th century, however, Middle Japanese was spoken. During this period of time, moraic obstruents (gemination) and moraic coda nasal (/N/) appeared. Also, during this period the conjugation for adjectives and verbs started to produce geminations in order to avoid CVCV clusters in Native Japanese. The Japanese limits manner of articulations, therefore this

\footnotetext{
${ }^{8}$ Past Tense can be made by adding a particle /ta/ to the verb stem.
} 
phenomenon emerged; in order to invent new sounds from different languages. According to Kawagoe (2015), in Sino-Japanese, only voiceless obstruents, such as /p/, /t/, /k/, /s/, / / /, /t $/$, and /ts/ are geminated. Kawahara (2015) states this is because the air pressure from the vocal vibration makes it difficult to produce voiced gemination. In loanwords, however, both Kawahara (2015) and Kawagoe (2015) address that voiced geminations do exist. For instance, the English word 'head' becomes /hed:o/, and 'egg' becomes /eg:w/. Kawagoe (2015) addresses that according to Kitahara (1997), there are three conditions that make gemination happen in loanwords: Segmental condition, Contextual condition, and Word-final condition. (1)

(1) Conditions for Geminates in Loanwords (Kitahara, 1997)

i. Segmental Condition: only obstruents can be geminated. Therefore, no sonorants can be geminated. (example: 'cap' $\rightarrow$ [cap:u], 'pet' $\rightarrow$ [pet:o], 'ham' $\rightarrow *[$ ham: w])

ii. Contextual Condition: the preceding vowel of the target consonant should be a short vowel. It can be neither a long vowel nor an epenthetic vowel. (example: 'hit' $\rightarrow$ [hit:o], 'heat' $\rightarrow *[$ hit:o])

iii. Word-final Condition: the target consonant should be in the word-final position. (example: 'cap' [cap: u], 'captain' *[cap:uteN])

In addition to these, Kawagoe (2015) mentions that there is an exceptional condition where voiced obstruents can be geminated. When the source word has more than one voiced obstruent, such as 'bed' and 'bag' in English, the final consonant is likely to undergo devoicing and gemination. Therefore, the outcomes for these two English source words are [bet:o] and [bak:u]. Overall, it is clear that geminations happen under various circumstances in Japanese, especially in loanwords. In this section, the history and features of geminated consonants were reviewed. It 
is determined that in Japanese pitch accents cannot be placed on the geminated consonant.

Considering pitch accents is key for reaching the goal of this study; understanding the emergence of abbreviation variations regarding abbreviations in Japanese.

\section{3-2 Accents}

Kawhara (2015) indicates that loanwords have distinctive accents from Japanese native words. Kubozono (2008) determined that $93 \%$ of the loanwords are accented while only $29 \%$ of the native words are accented. Several accentual types can be found in loanword adaptation, and Kawahara (2015) addresses some of them: the first being "default accent." According to him, borrowed words do not have a lexical specification for accents, therefore Japanese phonological grammar can determine where to insert them. Thus, many loanwords have its high pitch accent on the antepenultimate mora; for example, 'Christmas' [kurisumasu] and 'Australia' [o:sutoraria]. There are, however, exceptions. When the antepenultimate mora is heavy (e.g. geminations, coda nasals, or long vowels), the pitch accent would be one mora before the antepenultimate (e.g. 'pineapple'[painap:uru] and 'purple' [pa:puru]). Second, bimoraic loanwords, such as 'moca', tend to have high-low accentuation. Therefore, the word becomes [moka] in Japanese. This pattern applies to the bimoraic clipped words. For instance, the English word 'chocolate' has its accent on /re/, /t fokore:to/, however, an initial mora would have an accent after truncation, [t]oko]. Third, if the source words have low-high sequence, the accent tends to fall on the initial mora; e.g. 'Hawaii' [hawai] and 'sedan' [sedan]. Finally, there is a special pattern for words containing epenthetic vowels. As mentioned above, epenthetic vowels are inserted in order to follow the Japanese phonological rules when adapting loanwords. Kawahara (2015) illustrates examples. When an initial mora includes an inserted vowel, the accent is not placed on the inserted vowel. For instance, the English word 'twin' would become 
[tsuiN], and 'gray' becomes [gure:]. ${ }^{9}$ Although there are some other exceptions, these patterns suffice to explain the most frequent types of adaptations. Clipping in Japanese was mentioned briefly above (e.g. an English word 'chocolate'). In loanword adaptations, the clipping process is crucial to focus on. It would seem that different dialect speakers certainly have their own preferences for abbreviating words.

\section{3-3 Abbreviation}

According to Maynard (1997), Japanese has amassed a large number of loanwords from multiple languages, the most words coming from English (p.66). Irwin (2011) claims that there are three types of abbreviations in Japanese: mora clipping, compound reduction, and roman alphabet acronyms. Examples of these abbreviation can be found in Table 5 (p.71).

Table 5: Clippings in Japanese

\begin{tabular}{|l|l|l|}
\hline Original Word & $\begin{array}{l}\text { Japanese } \\
\text { (without shortening) }\end{array}$ & Shorten Version \\
\hline Chocolate & /tfokore:to/ & [tfoko] \\
\hline Personal Computer & /pa:sonaru koNpjur:ta:/ & [pasokoN] \\
\hline Universal Studio Japan & $\begin{array}{l}\text { /juniba:saru sutadzıo } \\
\text { dzapaN/ }\end{array}$ & [jur:esudđ̧e:] (USJ) \\
\hline
\end{tabular}

Maynard also proposes three main types of clipping in Japanese: back, fore, and middle clipping (Table 6) (p.71).

\footnotetext{
${ }^{9}$ Bold type indicates sounds with high pitch accents.
} 
Table 6: Clipping types in Japanese (Irwin, 2011)

\begin{tabular}{|l|l|l|}
\hline & Original word & Shorten version \\
\hline Back Clipping & /t fokore:to/ 'chocolate' & {$[\mathrm{t}$ foko $]$} \\
\hline Fore Clipping & /arubaito/ 'part time job'10 & {$[$ baito $]$} \\
\hline Middle Clipping & /moruhine/ 'morphine' & [mohi] \\
\hline
\end{tabular}

Irwin (2011) mentions that back clipping is the most prominent in Japanese. Furthermore, heavysyllable ending is avoided in loanwords. Although two-mora words are the most preferred, heavy syllables tend to remain in three-mora and four-mora words (e.g. 'permanent'[paama], 'sentimental' [seNtfi], and 'intelligent' [iNteri]) (p.74). According to Irwin, the word is usually clipped before accented moras (e.g. 'terrorism'/terorizumu/ $\rightarrow$ [tero]). However, when the first or second mora are accented, those words are clipped into two moras ('festival' /\$esutibaru/ $\rightarrow$ /[фesu] $]$ ). These are called 'vowel constraints' (p.75-76). As mentioned above, Japanese requires $\mathrm{CV}$ patterns, with the exceptions of geminations and long vowels. Therefore, in words such as

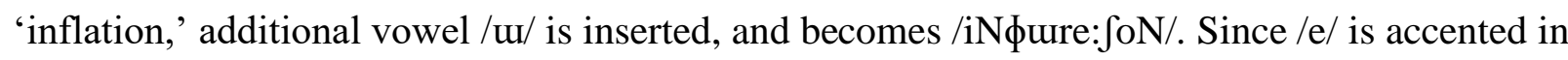
the original word, by following the vowel constraint, [iNфuu] would be expected as the output; however, since the vowel/w/ is epenthetic, it would be clipped one mora after the accented

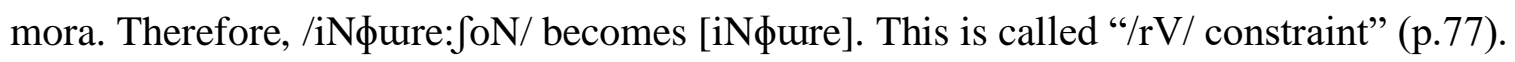

Ito (1990 p.215) proposes that "loanword abbreviations seem to fall into similar twomora and four-mora patterns." For instance, /konekufoN/ 'conncection' is abbreviated [kone] and /haNkatfi: $\phi u /$ 'handkerchief' is [haNkatfi]. According to Ito and Mester (2015 p.384), these

\footnotetext{
${ }^{10}$ Loanwords come from multiple languages; e.g. German
} 
abbreviations happen because Japanese follows "a bimoraic foot template.” Ito and Mester (2015) indicate that feet should be composed of two moras; either a heavy syllable or two light syllables. This applies not only for abbreviations of loanwords but also for native Japanese, SinoJapanese, and mimetics. ${ }^{11}$ Therefore, both [kone] 'connection' and [pasokoN] 'personal computer' have bimoraic feet. In addition to these two types of templates, Ito and Mester (2015) address another template: foot and a light syllable. For example, an English word like 'animation' becomes [anime] in Japanese. /ani/ has two moras, and /me/ is one mora, that has light syllable. Likewise, 'McDonald's' becomes [mak:u]. /mak:/ has two mora, which is a foot, and /w/ has one light mora at the end. Ito and Mester (2015) note that feet should be located on the left of the word. Ito (1990) also mentions that phonological or morphological rules of English do not affect shortening patterns; Japanese rules are inserted. Labrune (2002) indicates that as for compounding words (e.g. /pa:sonaru konpyuuta:/ 'personal computer' $\rightarrow$ [pasokoN]), the abbreviation pitch accents are different depending on the numbers of moras. In terms of compound sounds, Ito (1990) mentions that they are likely to be shortened by taking the first two moras from each word. For instance, /sarada doref:iNgu/ 'salad dressing' becomes [saradore](p.229).

In this section, the ways of clipping Japanese words were described. There are mainly three types of ways to clip the words; back, fore, and middle clipping. Depending on the heavy or light syllables, or the accents of the original words, the outcomes would be different although two or four-mora words are most likely preferred when the original words only consist of light syllables. Phonological aspects of Japanese have been observed so far. Now the history of the

\footnotetext{
${ }^{11}$ Mimetics are the descriptions of the sounds in Japanese.
} 
Japanese language will be discussed. It can be assumed that lexical and social histories have been affecting variations of loanword adaptations.

\subsection{History of Japanese Language}

\section{4-1 Japanese Lexicon}

In Japanese, there are four types of lexicons: native Japanese, Sino Japanese, mimetic expressions, and loanwords. According to Pinter (2015), Sino Japanese came from China roughly from the $7^{\text {th }}$ to $11^{\text {th }}$ centuries. Phonological changes have occurred since Japanese began to borrow words from Chinese. This concept will be discussed in the next section. In fact, loanwords from other languages, not just Chinese have affected Japanese phonology. Restrictions and constraints for adapting source words will also be discussed in the following sections.

\section{4-2 Language Evolution}

When thinking about Japanese orthographic sounds, it is not difficult to find some combinations of an irregular consonant and a vowel. There are five vowels in Japanese: /a/, /i/, /u/, /e/, and /o/. The main consonants are $/ \mathrm{k} /, / \mathrm{s} /, / \mathrm{t} /, / \mathrm{n} /, / \mathrm{ç} /, / \mathrm{m} /, / \mathrm{j} /, / \mathrm{r} /, / \mathrm{w} /$ and $/ \mathrm{N} /$. Besides single vowels and coda nasal /N/, Japanese usually follows a CV pattern. Therefore, the consonants cannot be counted as one mora on their own. (Table 7) 
Table 7: Japanese Sound Chart

\begin{tabular}{|l|l|l|l|l|l|l|l|l|l|l|}
\hline & k & s & t & n & ç & m & J & r & w & N \\
\hline A & ka & sa & ta & na & ça & ma & Ja & Ra & wa & \\
\hline I & ki & fi & t $\mathrm{i}$ & ni & çi & mi & & Ri & & \\
\hline ü & ku & su & tsu & nu & $\phi u$ & mu & ju & Ru & & \\
\hline E & ke & se & te & ne & çe & me & & Re & wo & \\
\hline O & ko & so & to & no & ço & mo & Jo & Ro & & \\
\hline
\end{tabular}

Some consonants undergo this irregular sound change; for instance, the second, third, and fifth columns from the left in the table 7 (s/, /t/, and /ç/). Shaded sounds need different consonants or insertion of an extra consonant; for instance, /t/ plus /w/ would be /tsw/ instead of /tw/. Painter (2015) explains that the emergence of Japanese consonants occurred from loanword adaptation and articulatory changes that associate with them. According to her, Old Japanese did not have irregular (shaded) sounds. However, as many words came into Japanese from Chinese, Japanese included those original sounds in order to make loanwords sound more similar to source words. Several new sounds from other languages have also been adopted into Japanese; for instance, the sounds such as /fa/ as in an English source word 'fan,'/ $\mathrm{fe} /$ as in 'Shakespeare,' and /tsa/ as in 'pizza' exist in modern Japanese. Table 7 only includes the sounds that can be used for native and Sino Japanese words. In the modern era, Japanese people try to match the same sounds as in source words. Therefore, an inventory of the modern Japanese language, including all borrowed sounds, would appear to be more complex than basic Japanese. In addition to a unique international collection of sounds, regional jargon and slang has been coined over time, further adding to the complexities of the Japanese language. Many native Japanese speakers consider 
these local phrases and abbreviations to be specific to young adults. In fact, as mentioned in the introduction section, the lexicon Wakamono Kotoba is used mainly by young adults in Japan.

\section{4-3 Wakamono Kotoba}

Kuwamoto (2002, p.113) explains that Wakamono Kotoba is a sort of jargon used by young people living in Japan. The lexicons usually originate from other jargons, especially from celebrities on TV. They spread though Japan via TV programs, comic books, and magazines. For the definition of Wakamono Kotoba, Kuwamoto (2002) mentions that it is used by young people whose ages range from the late teens to the early twenties. ${ }^{12}$ The use of these lexicons are restricted to people who belong to certain demographics. Therefore, terms that are ubiquitous for the younger generation must be developed in Japanese. Convenience stores, fashion boutiques, and fast food chain restaurants are examples of this trend. There are several types of Wakamono Kotoba according to Fang (2013, p.137-140), using classic Japanese, adding affixes, using English alphabets (e.g. "to ignore the atmosphere"/ku:ki jomenai/ becomes "KY" [ke:wai]), and shortening words. Irwin (2011, p.72) says that "Truncation processes are highly fluid and often confined to jargon, slang, youth speech and dialect." Mori (2002) defines Wakamono Kotoba as millennial campus language and highlights the relevance of abbreviations in their speech. Fudano 2019 (personal communication) claims that abbreviation is not specific to the younger generation, but elderly people do not have a manner to widespread their new jargons. Therefore, he admits that younger people tend to take advantage of this and generate new words which spread quickly throughout the country. It is interesting that within Wakamono Kotoba, variations also exist depending on the region. To figure out why loanwords vary among young people, it is

\footnotetext{
${ }^{12}$ Although other groups like computer geeks and mah-jongg enthusiasts may use more specific lexicon, this study will focus on the jargons used more widely by Japanese people, especially, young adults in Japan.
} 
necessary to examine the history of Kansai dialect, as it correlates with variation in present-day Japanese.

\section{4-4 History of Kansai Dialect}

In this section, the background information of Kansai dialect is briefly discussed. Kansai dialect is one of the most prestigious dialects in Japanese, despite the recent decrease in popularity. When discussing the dialects, Kansai dialect is often credited as the most famous, even legendary. Although the Kansai dialect is categorized as one prestigious dialect in Japanese, there are five sub-dialects within the Kansai area. ${ }^{13}$ Sanada (2018) indicates that they all have slight differences, such as lexical terms, conjugations, and sound changes. There are two reasons why Kansai dialect remains as one of the most prominent dialects: its place in Japanese history and connection to modern society. Ramsey (1979) states around the $8^{\text {th }}$ century in Kyoto, the household domestics transcribed the pitch of Japanese words. These transcriptions correspond to modern Kansai pitch. Ramsey (1979, p.158) continues to say, because Kyoto was once the capital of Japan, speakers of the dialect were considered to have a privileged status. In terms of modern aspects, the Japanese comedy boom has been shifting the image of Kansai dialect in a positive way. Osaka is one of the prefectures in the Kansai area, and according to SturtzSreetharan (2015, p.429), "After the 1980s, the image of Osaka dialect shifts to begin associated with owarai kotoba (the language of laughter) and fun. This image rehabilitation is thought to be a result of the manzai comedy boom." In fact, there are many comedians from the Kansai area simply because the area became a representation for comedy. Therefore, many

\footnotetext{
${ }^{13}$ If more specific details are taken into account, there are more types of dialects within Kansai dialect.
} 
Japanese people hold a stereotype that Kansai speakers have a good sense of humor just because there are countless famous comedians from that area.

Sanada (2018, p.7-8) mentions another possible reason why the Kansai dialect remains strong compared to other dialects. According to him, the center of politics has been moved to Edo, which is current Tokyo, around the $17^{\text {th }}$ century. At this moment, many dialects were mixed in Japan, which means there was no standard Japanese dialect. Around the same time, samurai clans made a standard dialect which gradually spread throughout the Edo area. Since this "standard dialect" became the most significant dialcet in Japan, people from the east began to think they were more privileged than people from the west. On the other hand, the Kansai speakers united themselves to keep their traditional accents and their own dialect. This is why Kansai dialect and Tokyo speech still differ more than any other dialects in Japan.

Considering the dialectal differences and the phonological processes discussed in previous sections, the purpose of this study is to see how variations among young people occur in the west and the east areas of Japan, with an emphasis on loanwords. Just like their native dialects, loanwords and even the abbreviated versions of them differ from region to region. Section 2 describes the methodology used to the study loanword adaptation. The instruments include a perception test, an acceptability judgement test, and a production test. The purpose of having perception and acceptability tests is to determine if Japanese speakers are aware of differences in their dialects and if they have any preferences regarding prosodic features, such as pitch accents. Moreover, by having a production test, more detailed patterns or preferences can be observed. Section 3 contains the results, section 4 incorporates discussion, and section 5 contains the conclusions. 


\section{Methodology}

The aim of this study is to examine Japanese dialectal variations for loanword abbreviations.

Considering the observations addressed above, it can be assumed that younger generations might affect the emergence of variations. Hence, Japanese college students from both Kansai (west) and Nagoya (east) were tested. Tests were conducted to see prosodic features of dialects and the subjects' awareness for the variations.

\subsection{Subjects}

In order to analyze phonological variations in youth language with specific interest on abbreviations and pronunciations, three tests were conducted. A total of 121 subjects participated in the study. To study eastern dialect, 53 participants from Kinjo Gakuin University in Nagoya were observed. All subjects were female. To study western dialect, 68 participants from Kansai Foreign Language University in Osaka were observed. Half were male and half were female. ${ }^{14}$ All subjects were ages 19 to 22 .

\subsection{Experiments}

\section{2-1 Perception Test}

For the first test, participants listened to an audio recording in which a speaker pronounced 15 shortened words in both the eastern and the western dialects. Both eastern and western words had the characteristics explained in section 1.3; for instance, high pitch was put on the initial mora for eastern words, but on the middle mora for the western words. Many words were clipped into

\footnotetext{
${ }^{14}$ Participants are from colleges where either Kansai ben or Nagoya dialect are spoken, but their actual hometown might be outside of Nagoya or Kansai. In fact, at Kinjo Gakuin University, there are high percentage of students from Mie prefecture, that is next to Nagoya.
} 
four moras, but some words were clipped into three moras by including coda nasal $/ \mathrm{N} /{ }^{15}$

Participants were asked to determine whether the speaker was from the east or the west. Two different kinds of words were used in the perception test, those that have already been adopted into Japanese and those that have not. ${ }^{16}$ On the answer sheet, words were presented without being shortened. The following question is an example of this test. Table 8 shows further examples of words used for this test.

(5) An Example Question for Perception Test

1. マクドナルド “McDonald's” (source word written in Japanese)

West $\quad$ East Neither of them

Table 8: Example of Words Used in the Perception Test

\begin{tabular}{|l|l|}
\hline Existing Words & English Words that haven't been adapted \\
\hline \hline $\begin{array}{l}\text { 'McDonald's' } \\
\text { /makudonarudo/ }\end{array}$ & $\begin{array}{l}\text { 'Heterogeneous' } \\
\text { /heterodziniasu/ }\end{array}$ \\
\hline$[$ makudo] & {$[$ hetero] } \\
\hline [mak:u] & {$[$ hetero] } \\
\hline $\begin{array}{l}\text { 'Family Mart' } \\
\text { [фamili: ma:to/ }\end{array}$ & $\begin{array}{l}\text { 'Kidnap' } \\
\text { /kidonap:u/ }\end{array}$ \\
\hline [фamima] $]$ & {$[$ kidona $]$} \\
\hline
\end{tabular}

${ }^{15}$ Examples of the words can be found in the appendix.

16 In a previous study, 15 native Japanese speakers were tested. The experiment included only nonsense words, however, the results had little to no variation, so they were not included here. 


\section{2-2 Acceptability Judgement Test}

For the second experiment, participants listened to a total of 17 words, with two variations each. None of the words used for this test have been adopted into Japanese yet. Their task was to rate the acceptability of those words on a 1 to 3 scale: 1 being the least acceptable and 3 the most acceptable. Table 9 includes examples of the words used in this test. Similar to the first test, word variations and different phonological features including the number of moras, nasal sound /n/, long vowels and double consonants (geminated sounds among others) were taken into account. The acceptability of words with different features was analyzed separately in order to see if those variations or features would be preferred by the specific area of speakers or not (Table 9).

Table 9: Examples of Words Used in the Acceptability Judgement Test

\begin{tabular}{|c|c|c|}
\hline Source Words & & \\
\hline $\begin{array}{l}\text { 'anthropology' } \\
\text { /aNsuroporodzi:// }\end{array}$ & [aNsu] & [asuporo] \\
\hline $\begin{array}{l}\text { 'gemstone' } \\
\text { /dzemusuto:N/ }\end{array}$ & [dzemusu] & [dुzemusus] \\
\hline
\end{tabular}

\section{2-3 Production Test}

For the last test, 68 subjects from the west and 20 subjects from the east participated. The remaining information including the ratio of gender and age are the same as the first two tests. Subjects were recorded shortening a total of 22 English words that have not been adopted by Japanese yet. All English words on the list were written in Japanese and were applied Japanese phonological rules and sounds but have not been shortened yet. In table 10, the examples of the word list are listed. 
Table 10: Examples for the Production Test

\begin{tabular}{|l|l|l|}
\hline Source Words & Japanese & Pronunciation \\
\hline Apothecary & アポセカリー & [aposekari:] \\
\hline Kidnap & キドナップ & [kidonap:u] \\
\hline
\end{tabular}

\section{2-4 Additional Questions}

After the tests, participants filled out a questionnaire with the following questions ${ }^{17}$ : "Do you think there is any difference between eastern and western dialects in Japanese? If so, why? "Do you think abbreviation is convenient? Why?" "How/ where/ from who do you learn these abbreviations?" The questionnaire was designed in order to complement the other three tests and develop a better understanding of Wakamnono Kotoba, especially in abbreviations.

\section{Results}

\section{3-1. Perception}

For the perception section, the participants listened to 15 words from each area and chose where the speaker was from. The figure shows the overall result. The blue portions show the expected answers based on the phonological characteristics of the words. Orange shows the unexpected answers.

\footnotetext{
${ }^{17}$ Actual questions are in the appendix
} 
Figure 2: Overall Results: W=West: Kansai E=East: Nagoya

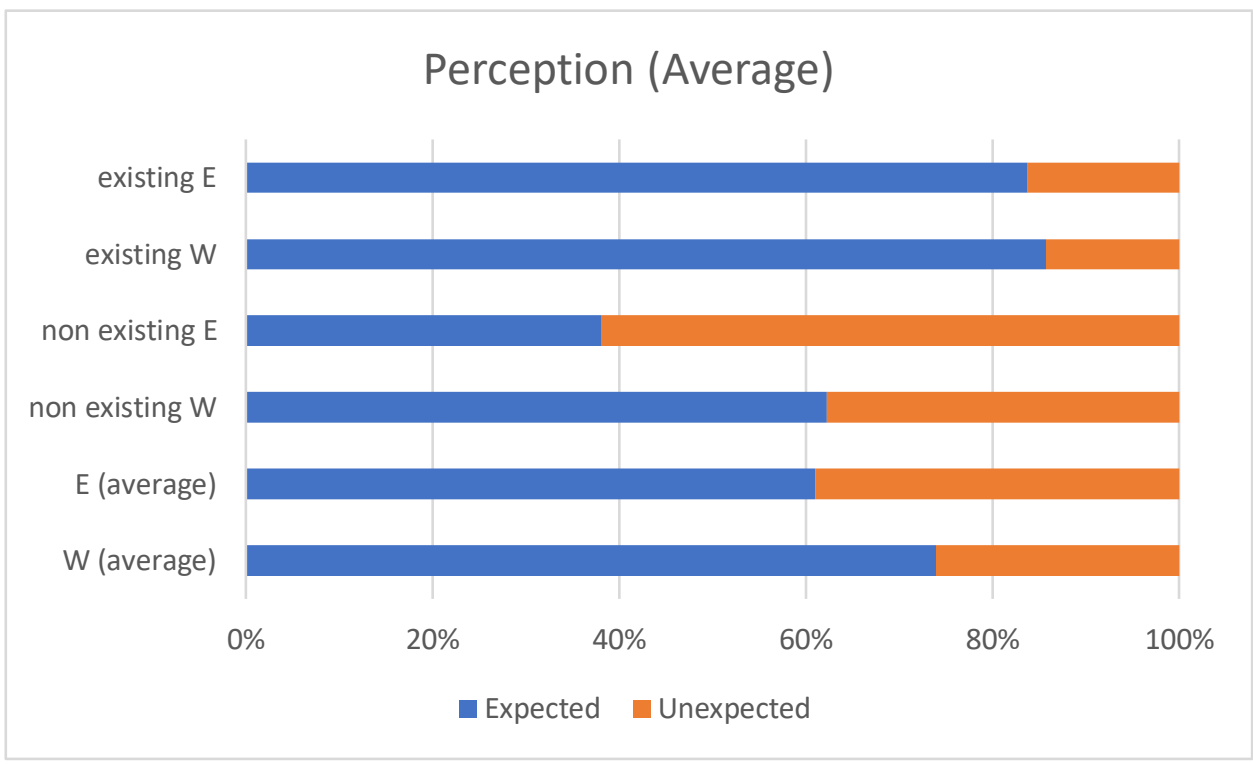

Figure3: East

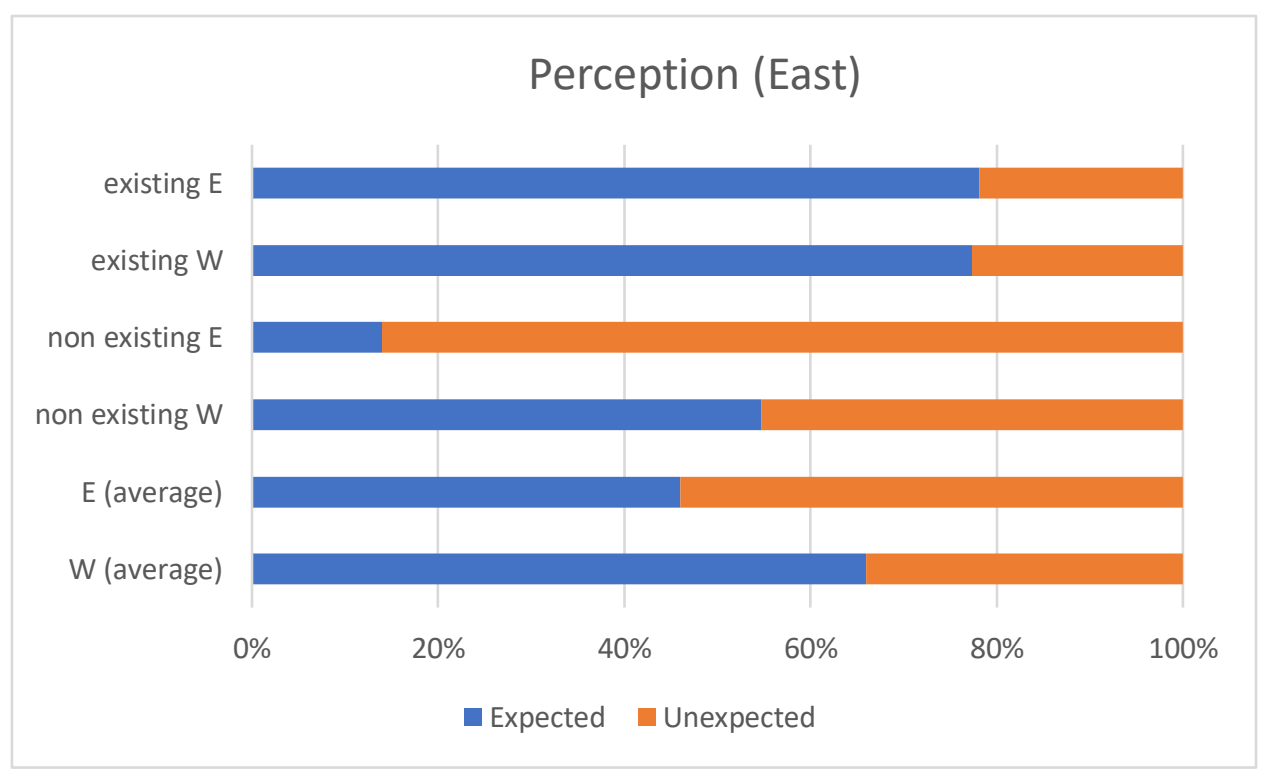


Figure 4: West

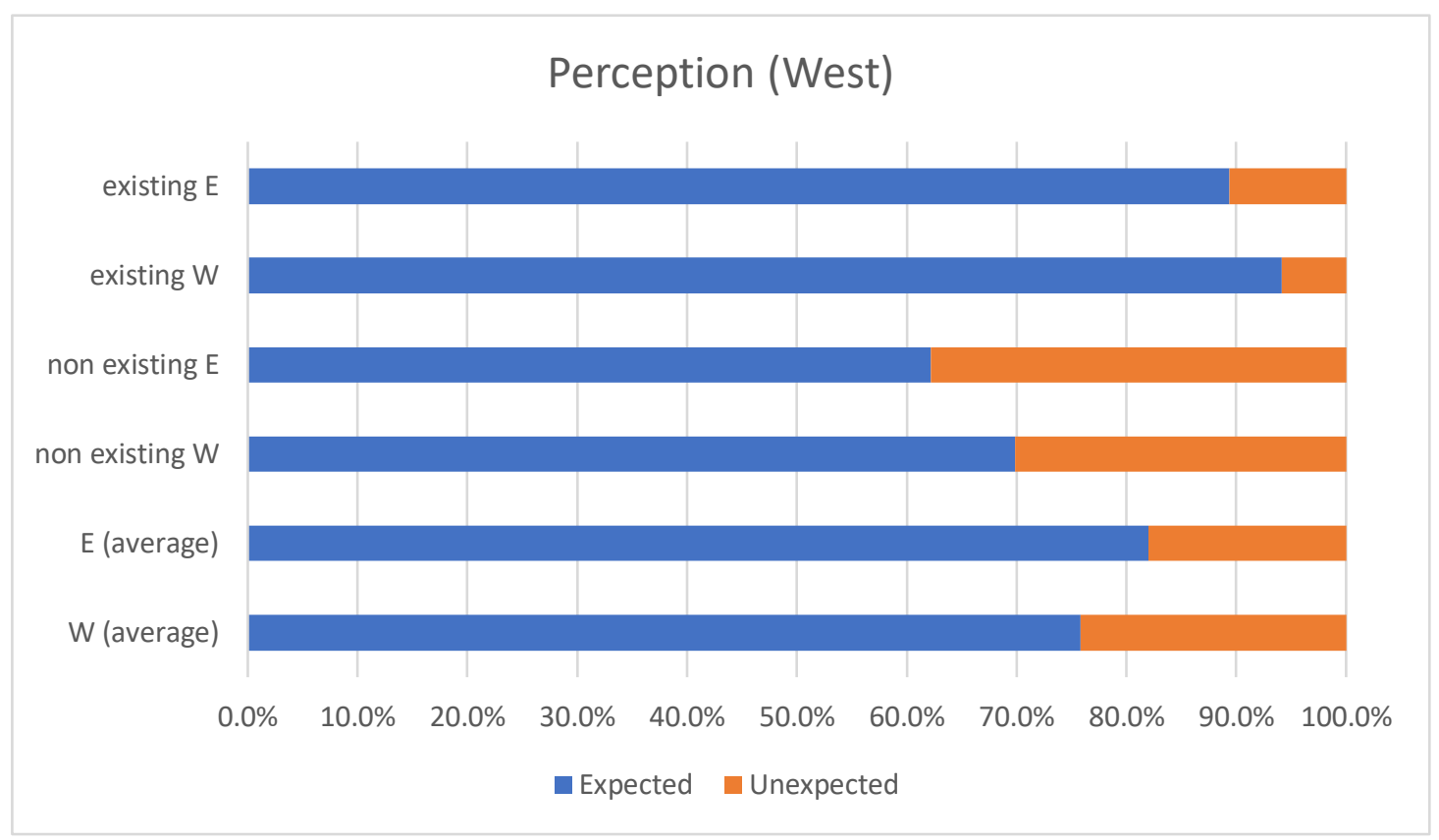

It is clear that the words with a western pitch were overall easier to recognize. Inversely, participants found that eastern pitched words were, to at least some extent, harder to recognize. Depending on the region, one can see the obvious differences between the recognition of eastern and western dialects, with approximately $60 \%$ of people from the east failing to recognize words that resemble those produced by speakers of the eastern dialect. On the other hand, the subjects from the west seemed to not have as much difficulty distinguishing whether the speaker was from east or west.

\subsection{Acceptability}

Regarding the acceptability test, subjects were asked to grade acceptability of each word on a 1 to 3 scale. 1 being the least and 3 being the most acceptable. The data was analyzed by region. 
Results were analyzed considering 3 aspects: the whole word, the pitch accent, and the number of moras. Results are illustrated in figures 5a-6b.

Figure 5a: Acceptability Judged by Pitch Accents

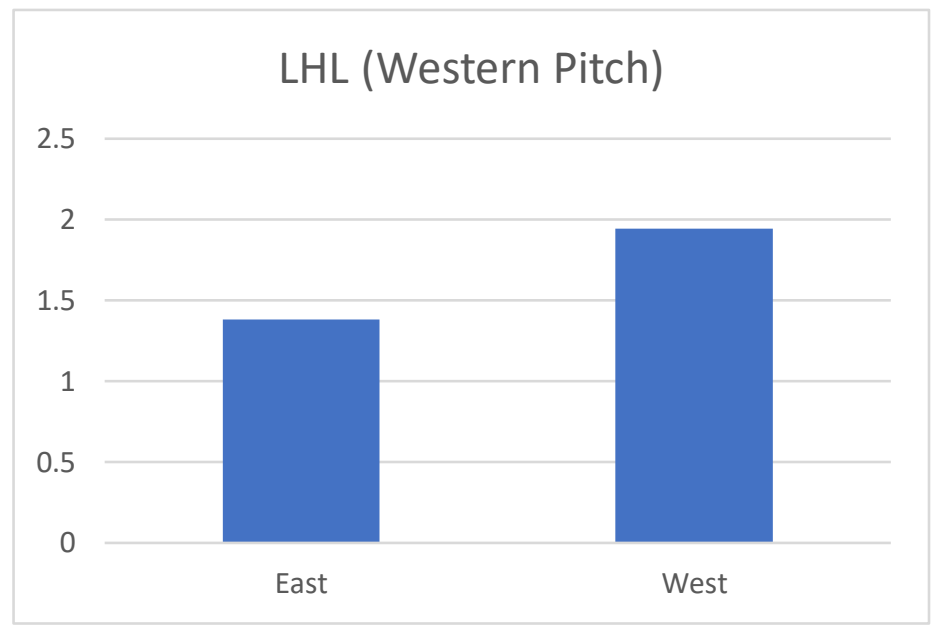

Figure 5b: Acceptability Judged by Pitch Accents

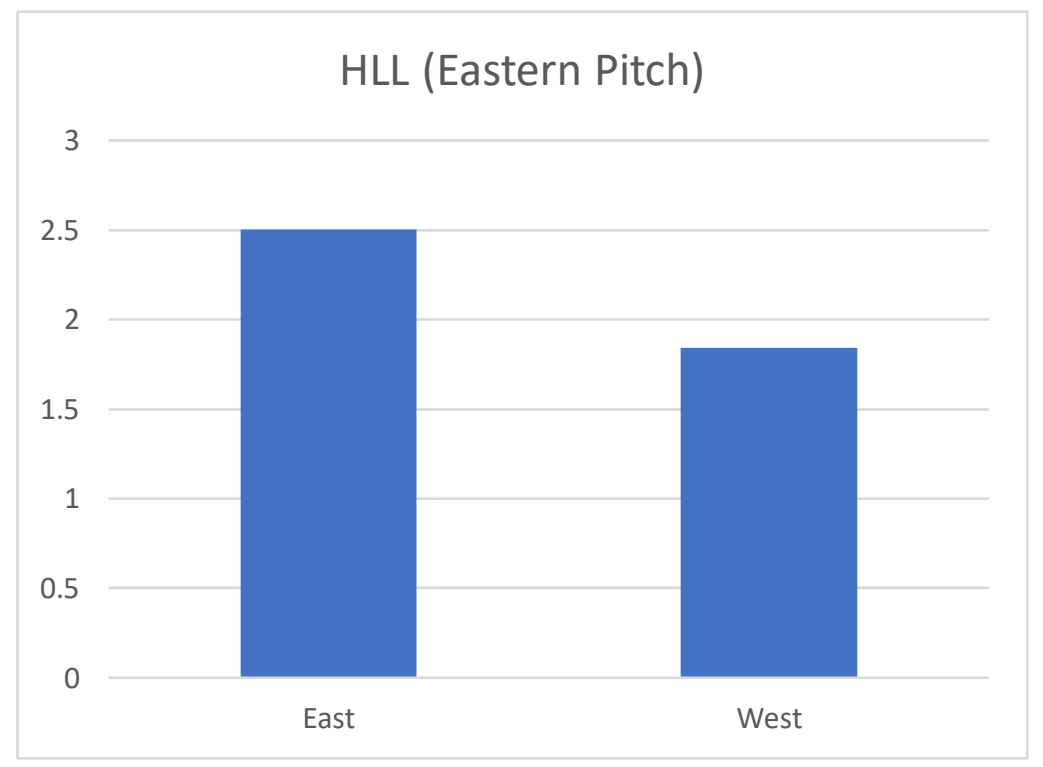


Figure 6a: Acceptability Judged by the Number of Mora

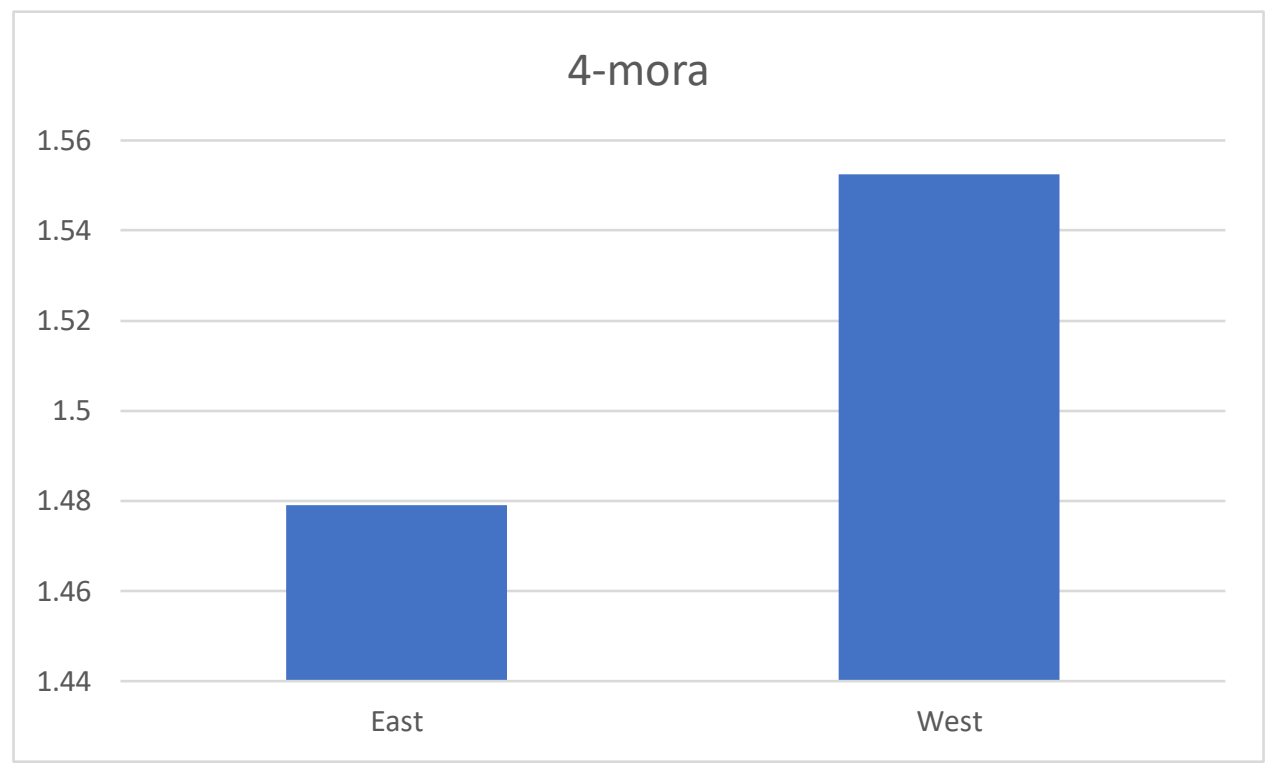

Figure 6b: Acceptability Judged by the Number of Mora

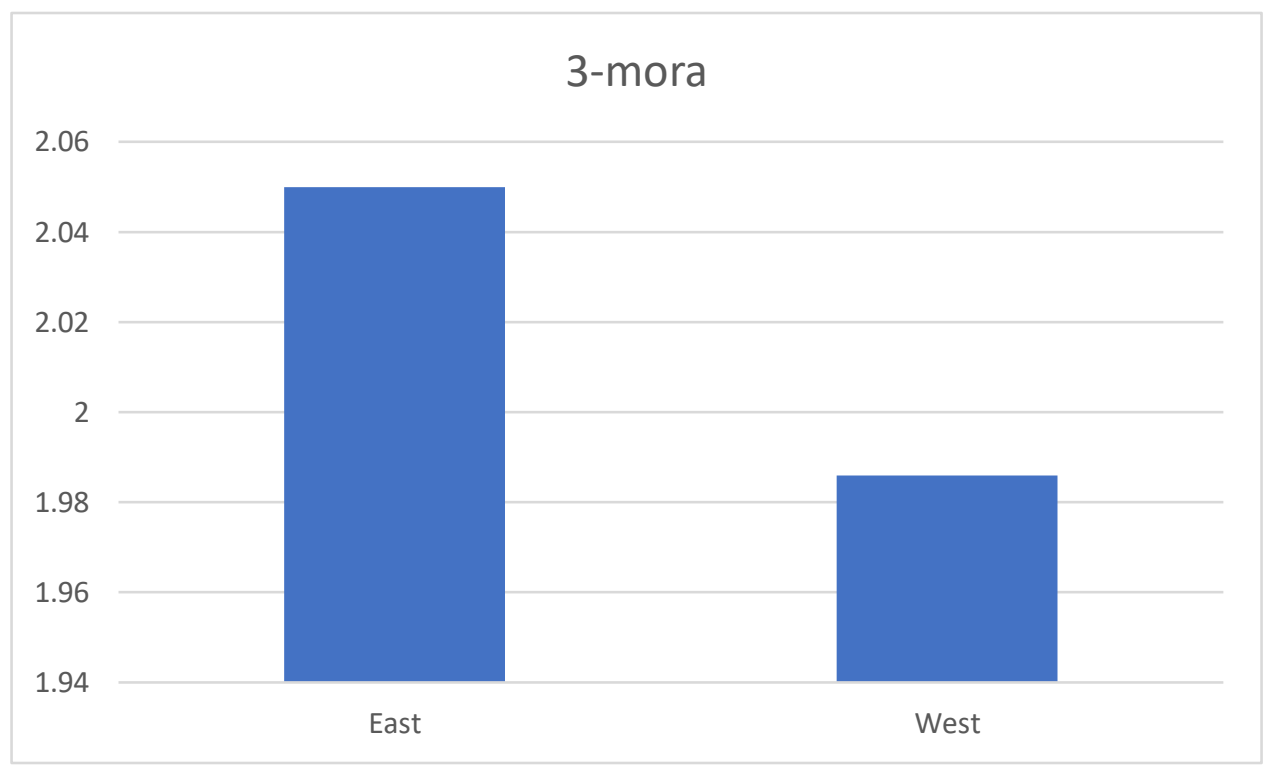

Clear differences regarding the preferences from both areas were found. As for the pitch accent, participants from both areas felt comfortable with the pitch accents of their own dialects. The western subjects preferred to place a high pitch in the middle of the word, whereas the eastern 
subjects did not show this same preference for the LHL accent. Regarding the numbers of mora, the western subjects preferred a four-mora abbreviation, a so called bimoraic foot. This preference oppses a three-mora abbreviations which includes a heavy mora, such as double consonants or the coda nasal /N/. The eastern subjects, however, tended to prefer 3-mora words more. This result opposed early prediction that western speakers would prefer three-mora clippings over four-mora clippings. This expectation was based on the fact that Kansai speakers place a high pitch accent on the penultimate. An example of this is the loanword abbreviation [sebuN] from "seven eleven."

\subsection{Production}

In this test, the subjects were recorded shortening 22 English words in order to discern regional differences in their abbreviations. Speakers used a wide variety of strategies to shorten the words. Both Kansai (west) and Nagoya (east) speakers tend to clip the source words into three and four-mora clippings. There was no distinct difference between Nagoya and Kansai speakers in showing the preference of heavy moras, such as geminations, coda nasals, or long vowels. Subjects from both areas produced words that include heavy moras almost equally. From here, the results emphasizing pitch accent preferences, the number of moras, and compounds will be discussed. ${ }^{18}$

\footnotetext{
${ }^{18}$ Answers that were not abbreviated at all and impossible to understand were exempted from the data.
} 


\section{3-3.1 Accents for Three-mora Words}

Table 11: Accent Pitch in 3-mora words

\begin{tabular}{|l|l|l|}
\hline & Nagoya & Kansai \\
\hline HL & $92.9 \%$ & $69.2 \%$ \\
\hline LHL & $5.6 \%$ & $21 \%$ \\
\hline LH & $1.5 \%$ & $9.8 \%$ \\
\hline
\end{tabular}

Regarding pitch accents, LHL accents were more prevalent among speakers of Kansai dialect in comparison to speakers of Nagoya dialect. Nagoya speakers tended to have a high pitch accent at the beginning of the word instead of on the penultimate syllable. The results show that more than 90\% of Nagoya speakers had HL sequences among 3-mora words. Regarding Kansai speakers, although more than half of them showed HL patterns, it is clear that they also showed a stronger preference for the LHL accent pattern than the other group. ${ }^{19}$

\section{3-3.2 Accents for Four-mora Words}

In Table 12, the results of four-mora word preferences can be seen. While the HL sequence is the most common pattern, Kansai speakers do produce LHLL, LLHL, and even LLLH patterns more than Nagoya speakers.

\footnotetext{
${ }^{19}$ Graphs can be found in the appendix.
} 
Table 12: Accent Pitch in 4-mora Words

\begin{tabular}{|l|l|l|}
\hline & Nagoya & Kansai \\
\hline HL & $87 \%$ & $64.1 \%$ \\
\hline LHLL & $12 \%$ & $22.3 \%$ \\
\hline LLHL & $1 \%$ & $11 \%$ \\
\hline LLLH & $0 \%$ & $2.6 \%$ \\
\hline
\end{tabular}

Many words with same pitch accent patterns were found from both areas; however, Kansai speakers produced more pitch variations than Nagoya speakers. Nagoya speakers produced many four-mora words either with no accent or with an accent on the initial mora. Kansai speakers, on the other hand, produced words with accents either on a penultimate or on an antepenultimate which were hardly seen in Nagoya speakers' samples. 10 out of 22 words were presented in those patterns.

Overall, HL is the most common pitch accent pattern for both the east and the west. It is striking to see that Kansai speakers prefer LHL accentual patterns rather than placing a high pitch on the initial mora like Nagoya speakers. It was also surprising that placing a high pitch on the word-final position is more acceptable for Kansai speakers than Nagoya speakers. The overall results can be seen in the following table (Table 13). ${ }^{20}$

\footnotetext{
${ }^{20}$ Both LHLL and LLHL patterns are combined as LHL sequence in order to compare 3 and 4-mora words.
} 
Table 13: Overall Results of Perceptions (3 and 4-mora Words)

\begin{tabular}{|l|l|l|}
\hline & Nagoya & Kansai \\
\hline HL & $90 \%$ & $66.3 \%$ \\
\hline LHL & $9.2 \%$ & $27.9 \%$ \\
\hline LH & $0.8 \%$ & $5.8 \%$ \\
\hline
\end{tabular}

\section{3-3.3 Compound words}

Two compound words ('tax deduction' and 'joint stock company') were included among the 22 English words that have not been adopted into Japanese. Regarding the clipping patterns, both Kansai and Nagoya speakers exhibited back-clipping, leaving the head of the original word, and mid-clipping, leaving moras from the beginning and middle of the word. ${ }^{21}$ Overall results show what Irwin (2011) expected; middle clipping is the most favored clipping pattern. It was unexpected to see that even though Irwin (2011) mentions mid-clipping is typically preferred for compound words, the most favored truncation for Kansai speakers in the word 'tax deduction' was back-clipping. It might be because the first element in 'tax deduction' contains a double consonant while the second example 'joint stock company' does not. It was also surprising to see that Kansai people had a higher percentage for fore-clipping while no fore-clipped outcomes were seen among Nagoya speakers. The accent patterns and the number of moras did not show a noticeable difference between both areas. As mentioned before, heavy syllables are likely to remain after clipping processes in compound words also. As for 'tax deduction,'/takkusu didakwfoN/, for instance, $48 \%$ of Kansai speakers and $36 \%$ of Nagoya speakers answered /takkusu/ (Table 14-15).

\footnotetext{
${ }^{21}$ Examples are shown in table 6.
} 
Table 14: Clipping Types

a. "Tax deduction"

\begin{tabular}{|l|l|l|}
\hline Tax deduction & Nagoya & Kansai \\
\hline Back Clipping & $42 \%$ & $55 \%$ \\
\hline Fore Clipping & $0 \%$ & $2 \%$ \\
\hline Middle Clipping & $58 \%$ & $43 \%$ \\
\hline
\end{tabular}

b. Joint stock company

\begin{tabular}{|l|l|l|}
\hline Joint stock company & Nagoya & Kansai \\
\hline Back Clipping & $19 \%$ & $23 \%$ \\
\hline Fore Clipping & $0 \%$ & $0 \%$ \\
\hline Middle Clipping & $81 \%$ & $77 \%$ \\
\hline
\end{tabular}

Table 15: Overall Result for Compounds

\begin{tabular}{|l|l|l|}
\hline & Nagoya & Kansai \\
\hline Back Clipping & $31 \%$ & $39 \%$ \\
\hline Fore Clipping & $0 \%$ & $10 \%$ \\
\hline Middle Clipping & $69 \%$ & $51 \%$ \\
\hline
\end{tabular}




\section{3-3.4 Three or Four-mora?}

Table 16: Overall Results: Preferences for the Number of Moras

\begin{tabular}{|l|l|l|}
\hline & Nagoya & Kansai \\
\hline 3 mora & $48 \%$ & $41 \%$ \\
\hline 4 mora & $44 \%$ & $52 \%$ \\
\hline Others & $8 \%$ & $7 \%$ \\
\hline
\end{tabular}

In table 16, the preferences for the number of moras can be seen. There is a tendency for Nagoya speakers to prefer 3 moras and a clearer preference for Kansai speakers for 4 mora words. In 14 out of 22 words, Kansai speakers had a higher percentage of four-mora words. On the other hand, only 3 words had a higher percentage of 3-mora than 4-mora words. Speakers from both areas showed almost the same preference regarding the outcomes that have either fewer than 2 moras or more than 5 moras (Table 17). Furthermore, $60 \%$ of original words that have geminations, such as 'yashmak,' 'kidnap,' and 'witness' show speakers' strong preference for clipping into 3-mora words. 70\% of original words including long vowels were likely to be clipped into 4-mora words in both regions (e.g. 'manipulate,' 'orthography,' and 'zoologist'). Approximately $70 \%$ of speakers from both areas also shown that the original words that have a coda nasal tend to be abbreviated into 4 moras rather than 3 moras (e.g. 'landlord,' 'recommendation,' 'nobleman,' and 'fairground'). Since any significant differences between regions were not found regarding coda-nasal and geminations, the assumption that western speakers prefer three-mora words ([sebuire] from east vs [sebuN] from west) is difficult to confirm. In fact, the results showed that people from the eastern area strongly prefer three-mora words. 16 out of 223 -mora words were produced by both areas, and 11 out of 16 words had a 
higher percentage of production in eastern areas than western areas. The results are shown in Table 16. Preferences for words with more than 5 mora and words with fewer than 2 mora are also shown. Although the differences between the two areas are not always significant, Nagoya speakers produced abbreviations that have more than five moras more than Kansai speakers. As Fudano (2019) mentions, this might be because Kansai speakers prefer shorter words more so than Nagoya speakers. 
Table 17: Overall Results for Preferences of the Number of Moras (Production)

\begin{tabular}{|l|l|l|l|l|l|l|}
\hline \multirow{2}{*}{ Word } & Nagoya & & & Kansai & & \\
\cline { 2 - 7 } & 4 mora & 3 mora & 2 or 5 & 4 mora & 3 mora & 2 or 5 \\
\hline Catastrophe & $58 \%$ & $16 \%$ & $26 \%$ & $84 \%$ & $11 \%$ & $5 \%$ \\
\hline Apothecary & $11 \%$ & $89 \%$ & $0 \%$ & $20 \%$ & $78 \%$ & $2 \%$ \\
\hline Dermatologist & $26 \%$ & $42 \%$ & $32 \%$ & $45 \%$ & $22 \%$ & $33 \%$ \\
\hline Fairground & $74 \%$ & $21 \%$ & $5 \%$ & $73 \%$ & $17 \%$ & $10 \%$ \\
\hline Eclipse & $10 \%$ & $83 \%$ & $7 \%$ & $33 \%$ & $67 \%$ & $0 \%$ \\
\hline Governorship & $72 \%$ & $17 \%$ & $11 \%$ & $75 \%$ & $17 \%$ & $8 \%$ \\
\hline Heterogeneous & $42 \%$ & $53 \%$ & $5 \%$ & $34 \%$ & $64 \%$ & $2 \%$ \\
\hline Infection & $21 \%$ & $79 \%$ & $0 \%$ & $48 \%$ & $52 \%$ & $0 \%$ \\
\hline Registration & $63 \%$ & $37 \%$ & $0 \%$ & $56 \%$ & $38 \%$ & $6 \%$ \\
\hline Manipulation & $37 \%$ & $63 \%$ & $0 \%$ & $38 \%$ & $57 \%$ & $5 \%$ \\
\hline Nobleman & $100 \%$ & $0 \%$ & $0 \%$ & $90 \%$ & $8 \%$ & $2 \%$ \\
\hline Orthograph & $42 \%$ & $32 \%$ & $26 \%$ & $50 \%$ & $35 \%$ & $15 \%$ \\
\hline Pavement & $21 \%$ & $79 \%$ & $0 \%$ & $25 \%$ & $65 \%$ & $10 \%$ \\
\hline Recommendation & $58 \%$ & $42 \%$ & $0 \%$ & $72 \%$ & $20 \%$ & $8 \%$ \\
\hline Witness & $16 \%$ & $84 \%$ & $0 \%$ & $13 \%$ & $87 \%$ & $0 \%$ \\
\hline Widespread & $68 \%$ & $26 \%$ & $6 \%$ & $70 \%$ & $27 \%$ & $3 \%$ \\
\hline Yashmak & $5 \%$ & $90 \%$ & $5 \%$ & $11 \%$ & $67 \%$ & $22 \%$ \\
\hline Zoologist & $84 \%$ & $16 \%$ & $0 \%$ & $88 \%$ & $9 \%$ & $3 \%$ \\
\hline Landlord & $53 \%$ & $42 \%$ & $5 \%$ & $54 \%$ & $45 \%$ & $1 \%$ \\
\hline Kidnap & $0 \%$ & $100 \%$ & $0 \%$ & $5 \%$ & $92 \%$ & $3 \%$ \\
\hline $\begin{array}{l}\text { Joint stock } \\
\text { company }\end{array}$ & $63 \%$ & $6 \%$ & $31 \%$ & $85 \%$ & $5 \%$ & $10 \%$ \\
\hline Tax deduction & $53 \%$ & $26 \%$ & $21 \%$ & $67 \%$ & $8 \%$ & $25 \%$ \\
\hline
\end{tabular}




\subsection{Additional Questions}

The additional questions at the completion of the tests were added in order to complement the results, and to better understand why regional differences occur, and why these phenomena are specific to young adults.

\section{4-1. The Differences between East and West}

The answers from the questionnaire were quite remarkable. Most of Kansai and Nagoya speakers admitted they were aware of the differences between eastern and western dialects when adopting loanwords into Japanese. The main responses from the questionnaire regard the following themes: 1. Accents, such as variational accents (LHL, LH), and Kansai speakers prefer stronger accents; 2. Intonation or tones; for example, some participants answered that Kansai speakers tend to have rising tones towards to the end and their intonations are more distinctive than Nagoya speakers; 3 . Truncation styles; for instance, preferences for the length of the words; 4. Pronunciation; 5. Likelihood of dialect influence. Further results showed that Kansai speakers admitted that they prefer short words. Moreover, it was interesting to hear Nagoya speakers' opinion on Knasai dialect. Some of the Nagoya speakers referred to Kansai dialect as 'namaru' (dull) or 'kitsui' (overly direct). It can be assumed that Nagoya speakers are proud of themselves and their practice of "standard" Japanese and have privileges by speaking it. Furthermore, there were some responses alluding to Kansai dialect being "contagious." It is not uncommon that Japanese people easily pick up on Kansai dialect due to its catchy nature. 


\section{4-2. Where Do They Learn Abbreviations?}

Most participants learned abbreviations from friends, television, commercials, advertisements, SNS (Social Networking Service), family, school, and celebrities. Since many terms are coined and spread through those means, these responses were not very unexpected. However, some participants answered that they actually make up abbreviations by themselves. Of course, other generations could also invent their own abbreviations, however, like Fudano (2019) suggests, older generations can be weaker influencers because their ways to spread new terms are limited. On the other hand, young adults spread new words extremely quickly by using social networking such as Instagram, Facebook, and YouTube. Therefore, results suggest that abbreviations are an important part of millennials' speech.

\section{4-3. Why do you think the abbreviations are convenient?}

According to speakers' observations, it seems like there are positives and negatives for the use of abbreviations. 114 out of 121 subjects said that abbreviations sound friendly because source words are not something they are used to hearing. ${ }^{22}$ Therefore, by shortening the source words, they get closer to Japanese, sound more familiar, and they are easier to remember. They also believe that abbreviations make communication smooth. Abbreviations save time because they are shorter. It allows for faster online communication in which many platforms are restricted to character limitations, such as text message or Twitter. On the other hand, there are some participants who insist that they are inconvenient. First, it takes time to understand new words. Second, there are countless abbreviations in today's speech and are often confusing. Third, the use of abbreviations makes it difficult to communicate with their grandparents or older relatives.

\footnotetext{
${ }^{22}$ A few subjects said that it depended on the situation.
} 
There are limitless ways to shorten words and there are multiple rules to apply when adapting the words. Therefore, the many abbreviations in modern Japanese can potentially make personal communication complicated.

Overall, it was curious to see how western and eastern speakers consider themselves; if they think they have accents or not, for example. It was useful to know in what ways the participants learn new abbreviations. Their answers made it clear that younger people use more abbreviations than older people. It was also intriguing to see the different opinions on the convenience of abbreviations. Participants' answers and opinions were convincing enough to confirm that most young people use abbreviations to communicate in their daily lives.

\section{Discussion}

This study has observed Japanese phonological variations between regions with emphasis on prosodic features of loanword adaptations. Overall, this study confirmed that there are significant differences between two dialects in Japan regarding loanword adaptations, Kansai (west) and Nagoya (east). Speakers from both Kansai and Nagoya areas are aware of western and eastern dialects in the following aspects: intonations, pitch accents, pronunciations, stress, tones, and ways of truncations. Therefore, they can recognize each other's dialect. Kansai speakers, however, seem to have a stronger ability in recognizing the differences between the two dialects. In the perception test of existing loanwords, approximately $22.5 \%$ of Nagoya speakers chose unexpected answers whereas only $8.5 \%$ of Kansai speakers chose unexpected answers. Regarding non-existing loanwords, $60 \%$ of Nagoya speakers chose unexpected answers while only $20 \%$ of Kansai speakers chose unexpected answers. This is because Kansai speakers consider their unique dialect a privilege to speak, as mentioned in the history section (1.4-4). The 
test results show that regional variations are likely caused by two factors: phonological regional, and social influences.

First, in general, Kansai speakers are likely to prefer 4-mora words whereas Nagoya speakers prefer 3-mora words. When the source words have geminated consonants, both Kansai and Nagoya speakers showed the preference of 3-mora words. For instance, with 'witness'/wittonesul/, 70\% of both Kansai and Nagoya speakers answered /witto/. For 'tax deduction,'/takkusu didakufoN/, 48\% of Kansai speakers and 36\% of Nagoya speakers answered /takkusuu/. Kansai and Nagoya speakers both preferred 4-mora words when long vowels are included in the source words. This is because in compound words, according to Kawagoe (2015), the heavy mora stays prevalent during the clipping process. Based on his opinion, it seems that less phonological variations can be found when the original words have special prosodic features, such as long vowels, coda nasal, and geminated consonants.

Second, speakers from both areas prefer middle-clipping for words consisting of any number of mora. Although, Kansai speakers tend to put pitch accents on the penultimate or antepenultimate mora, whereas Nagoya speakers either have no specific high pitch accents or put high pitch accents on the first mora of the word. In fact, Kansai speakers expressed that LHL and LH patterns are more likely to be accepted compared to HLL, which Nagoya speakers preferred. This answers the study's introductory question in the introduction of why Nagoya speakers say 'McDonald's' /mak:u/ with a high pitch accent on the first mora and Kansai speakers say /makudo/ with a high pitch accent on the second mora. If Kansai speakers also adopted this word as /mak:u/, it would be impossible to follow a LHL rule that Kansai dialect uses. This is because the penultimate mora is a geminated consonant which cannot have an accent in Japanese phonology. Utilizing all results from this study, there are clearly defined preferences for the 
different dialects' speakers. The regional variations in dialects are not only results of phonology, but also a result of sociolinguistic aspects.

Individual pride, cultural identities, and social media all impact variations in loanword abbreviations. Participants expressed that abbreviations are useful and comfortable for them to communicate with others. They believe that abbreviations make communication smooth for many reasons (e.g. because they can type or speak more quickly, more information can be included when input is limited). Therefore, it seems that abbreviations promote more effective communication. Some participants, however, find abbreviations inconvenient or sometimes too complex. Abbreviated words potentially make communication difficult with people from older generations. Thus, the trend that abbreviations are widely used among young people rather than older people can be seen in Japan. Older generations have technological limitations in the spreading of trends while young generations spread new words through the Internet and SNS. Subjects expressed that they sometimes clip words to make up new ones. They learn abbreviations mostly from friends and SNS. Having this information, in addition to the regional variations that is widespread among all generations in Japan, Japanese young adults have different ways of truncations in loanwords depending on which dialect they speak.

All of these changes have appeared because of prosodic features that vary from region to region and social factors. Dialectal variations in loanword abbreviations can be observed by analyzing the results of this study. Throughout this investigation, other arguments were revealed and can be addressed in future research. These prospective studies will be explained in the next chapter. 


\section{Conclusion}

The initial goal of this thesis was to determine if there are differences in the adaptation of loanwords between the east side and the west side of Japan. What makes this research noteworthy is that even though loanwords come from different languages without Japanese phonological features, the outcomes have dialectal features. At the both phonological and the sociological level, there are dialectal differences between Kansai and Nagoya that generate trends of loanword abbreviations in Japanese.

Young adult speakers are aware of the differences between dialects in the aspect of linguistic features, such as truncation styles, accents, and pronunciations. The phonological level can be divided into three categories: the number of moras, clipping types, and pitch accents. Kansai speakers prefer 4-mora words and Nagoya speakers prefer 3-moras. Exceptions can be seen when the original words have either long vowels or geminated consonants. When the original words have long vowels, speakers from both areas prefer 4-mora whereas 3-mora words are preferred when they have geminated consonants. As for clipping, mid-clipping is preferred by both Kansai and Nagoya speakers; for instance, / peagura/ from the English word 'fairground.' Regarding pitch accents, Kansai speakers prefer LHL and LH sequences while Nagoya speakers show preference for HLL.

At the social level, the Kansai dialect remains prominent because of its clear historical and communal value. Kansai speakers are likely to show their pride by using their traditional dialect. When adapting loanwords, Kansai speakers still apply their phonological features that originally developed in Native Japanese. There is another integral social factor that adds to the separate natures of the two dialects. Many Nagoya speakers mentioned about how strong or peculiar a Kansai accent sounds. This makes them prideful of their own "standard" Japanese 
dialect, wanting further distance from Kansai dialect. Södergren (2014, p.15) indicates that this might also be because of the spread of Japanese media, such as television. According to her, television has given the image of Tokyo, or "standard" Japanese, a modern and correct connotation. Therefore, many Japanese people think that "standard" Japanese is "correct" and other dialects are "incorrect" or "less polite." Some Nagoya speakers even attribute negative labels to Kansai dialect, such the terms 'namaru' and 'kitsui.' Sanada (2018) mentions that the impression for Kansai dialect has been changing. According to him, after the Japanese comedy boom, people started to consider that Kansai dialect brings laughter and joy. Furthermore, since the Kansai dialect is a rhythmical dialect compared to "standard" Japanese, people also consider this dialect as friendly. Therefore, people from other regions use Kansai dialect in causal situations: creating a comfortable or fun atmosphere; making listeners laugh; and teasing others. Recently, Kansai dialect has been used among many younger generations as a tool to promote friendly communication. In fact, there are people who coin new terms by adding suffixes and pitch accents special to Kansai dialect, so called "Ese Kansai-ben" (fake Kansai dialect). There is also an option to choose Kansai dialect responses on Facebook. Sanada (2018) insists that the negative impression for Kansai dialect has changed to a positive impression because it has an ability to maintain the feeling of unity. This societal shift would be an interesting topic for a future linguistic study.

According to Sanada (2018), due to the development of public transportation, moving to other cities became much easier, and the differences between regional dialects have been getting smaller. He also mentions that this situation caused the standardization of dialects in Japan. Furthermore, the use of "standard" Japanese on the Internet and multimedia might be another reason to make young peoples' use of dialects slowly disappear. 
The results from this study can also contribute to the further research of Japanese phonology and sociophonetics. Just as Sanada (2018) explains that dialectal characteristics are getting less obvious, there are regions where multiple dialects are mixed because of geographical reasons. According to Sanada (2018), Mie speakers use the dialectal mixture from both the east and the west. The Mie prefecture is located between Nagoya and Kansai, so rather than displaying a strong distinct dialect, people from this region use the blend of the two dialects. In this study, the subjects were the students from universities in Kansai and Nagoya. However, subjects might have not originally been from these regions. It is possible students were raised in smaller towns outside of the targeted areas. Mie speakers, for example, could present a third variable, offering valuable data in similar studies. Furthermore, future studies can consider the history of abbreviations. Before SNS or text messaging were developed, people were already abbreviating words. Finding earlier examples of generational abbreviations would prove useful in future dialectal research. Regardless, these dialectal trends are at the risk of disappearing, making this linguistic research not just important but essential. 


\section{Bibliography}

Cutler, A., \& Otake, T. (1999). Pitch accent in spoken-word recognition in Japanese. Acoustical Society of America., 105(3), 1877-1888.

Doerr, N. (2015). Standardization and Paradoxical Highlighting of Linguistic Diversity in Japan. Japanese Language and Literature, 49(2), 389-403.

Fang, Y. (2013). A Study of Characteristic Expression Detectable in the Spoken Japanese of Youth. Nihon Gakkan. 16. 136-144.

Grenon, I. (2005). The status of the sound [z] in Japanese. Revue Langues et Linguistique, 31, 64-90.

Horio, K. Wakamono Kotoba ni mirareru gengo henka ni kansuru kenkyuu. [The study on language variations and changes in Japanese new words and phrases Wakamono]. Kyushu University Institutional Repository.

Irwin, M. (2011). Mora Clipping of Loanwords in Japanese. Journal of Japanese Linguistics 27, 71-81.

Ito, J. (1990). Prosodic minimality in Japanese. The Proceedings of the Chicago Linguistic Society. 26(2), 213-239.

Ito, J and Mester, A. (2015). Word formation and phonological processes. In H. Kubozono (ed.), Handbook of Japanese Phonetics and Phonology, 363-395. Berlin: De Gruyter Mounton. Kawagoe, I. (2015). The phonology of sokuon, or geminate obstruents. In H. Kubozono (ed.), Handbook of Japanese Phonetics and Phonology, pp. [79-119]. Berlin: De Gruyter Mounton

Kawahara, S. (2011). Aspects of Japanese loanword devoicing. Journal of East Asian Linguist, 20(2),169-194. 
Kawahara, S (2015). The Phonology of Japanese Accent. In H. Kubozono (ed.), Handbook of Japanese Phonetics and Phonology, pp. [445-492]. Berlin: De Gruyter Mounton

Kibe, Y. (2019). Nihongo Hoogen no Tayoosei- Akusento no Tiikisa-. Tokyo University of Foreign Studies School of Japan Studies Research Report, 1(5), 1-9. National Institute for Japanese Language and Linguistics

Kori, S. (2012). Gendai Osaka Hoogen ni okeru Teikishiki Akusento no Tokuchoo. [Acoustic Characteristics of the Low-beginning Type Accent in the Osaka Dialect]. The Phonetic Society of Japan. 16(3), 59-78.

Kuwamoto. Y. (2002). Production and Stability of Wakamono Kotoba. Akita Koto Kenkyu Kiyo. $38,113-120$.

Kubozonzo, H. (2008). Japanese accent. In Shigeru Miyagawa and Mamoru Saito (eds.), The $\backslash$ Oxford handbook of Japanese Linguistics, 165-191. Oxford: Oxford University Press.

Labrune, L. (2002). The prosodic structure of simple abbreviated loanwords in Japanese: A constraint-based account. Journal of the phonetic Society of Japan, 6(1), 98-120.

Maynard, S. (2011). Variation and Change in Nihongo. In Learning Japanese for Real: A Guide to Grammar, Use, and Genres of the Nihongo World. 20-28. University of Hawai'i Press.

Maynard, S. (1997). Styles and Varieties of the Japanese Language: Responding to Social Needs. In Japanese Communication: Language and Thought in Context. 49-82. Honolulu: University of Hawai'i Press.

Mori,Y. (2002). Formation of Three-mora Compound Abbreviations. Journal of the Phonetic Society of Japan, 6(1). 121-137.

National Institute for Japanese Language and Linguistics. (2002). Gairaigo ya ryakugo no 
chishiki [Knowledge of Loanwords and Abbreviation]. Retrieved from https://www.ninjal.ac.jp/archives/genzai/ishiki/kekka/2index/2-1/

Otake, T., Hatano, G., Cutler, A., and Mehler, J. (1993) 'Mora or syllable? Speech segmentation in Japanese', Journal of Memory and Language, 32(2). 258-278.

Otake, T. (2015), Mora and mora-timing. In H. Kubozono (ed.), Handbook of Japanese Phonetics and Phonology, 493-524. Berlin: De Gruyter Mounton.

Painter, G. (2015). The emergence of new consonant contrasts. In H. Kubozono (ed.), Handbook of Japanese Phonetics and Phonology,121-165. Berlin: De Gruyter Mounton.

Ramsey, S. (1979). The Old Kyoto Dialect and The Historical Development of Japanese Accent. Harvard Journal of Asiatic Studies, 39(1), 157-175. doi:10.2307/2718816

Sanada, S. (2018). Kansaiben jiten. [Cyclopedia of Kansai Dialect]. Tokyo: Hitsuji Shobou Södergren, S. (2014). "Metcha suki ya nen”: A socio linguistic attitude survey concerning the Kansai dialect. Retrieved from www.divaportal.org/smash/get/diva2:726707/FULLTEXT02

SturtzSreetharan, C. (2015). "Na(a)n ya nen": Negotiating Language and Identity in the Kansai Region. Japanese Language and Literature, 49(2), 429-452.

Warner, N. (1997). Recognition of accent patterns across dialects in Japanese. In Annual Meeting of the Berkeley Linguistics Society, 238(1), 364-375.

Yoshida, K. (2017). Tokai-chiiki Seibu Chihoo no Akusento ni okeru 'Osoagari' no Onseijitsugen no Tokuchoo. [The Characteristics of Late Rise Accents in Western Tokai Region]. Journal of the Phonetic Society of Japan 21, 43-48. 


\section{Appendix}

\section{Productions from East and West}

(Blue: East, Orange: West)

(1)

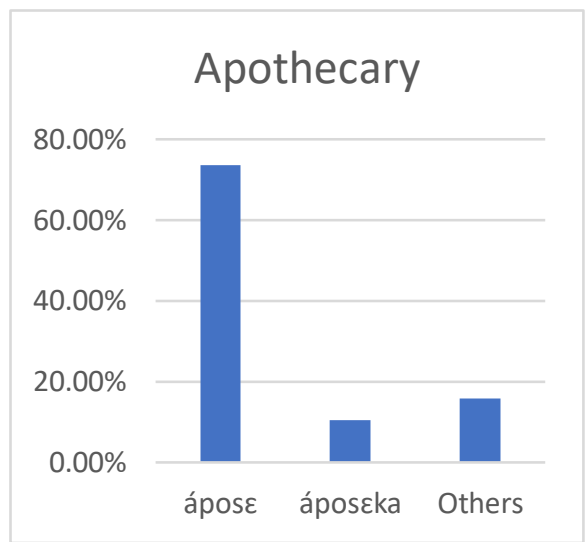

(3)

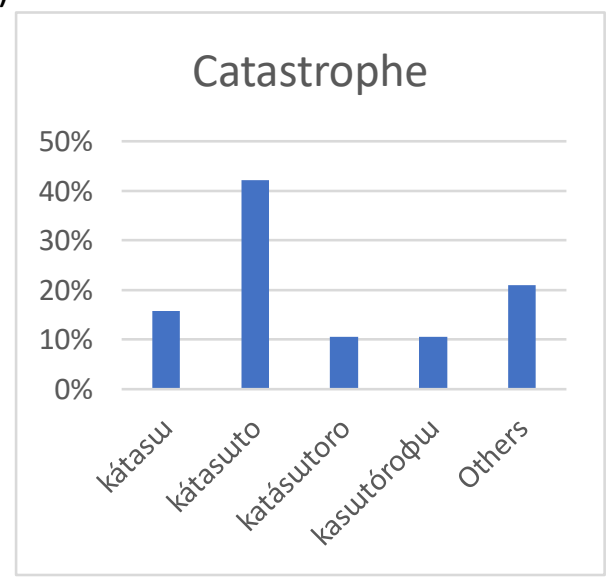

(5)

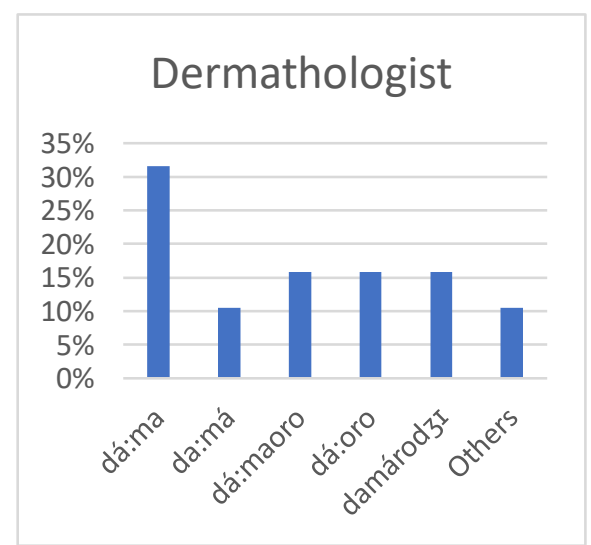

(2)

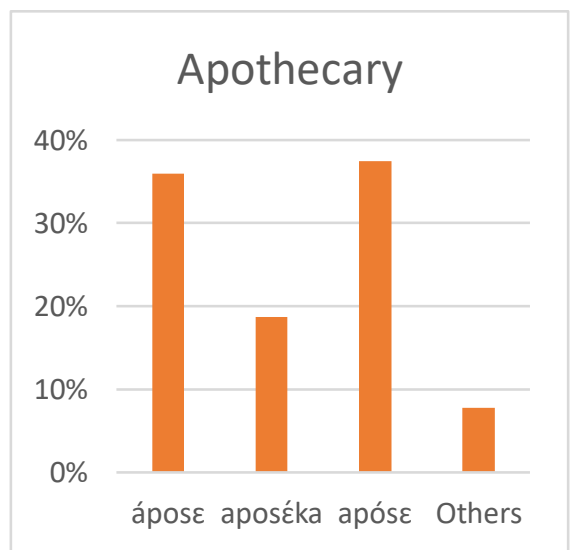

(4)

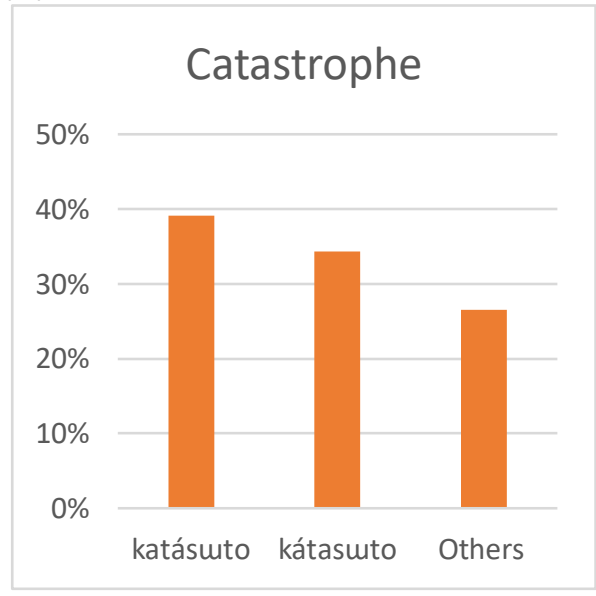

(6)

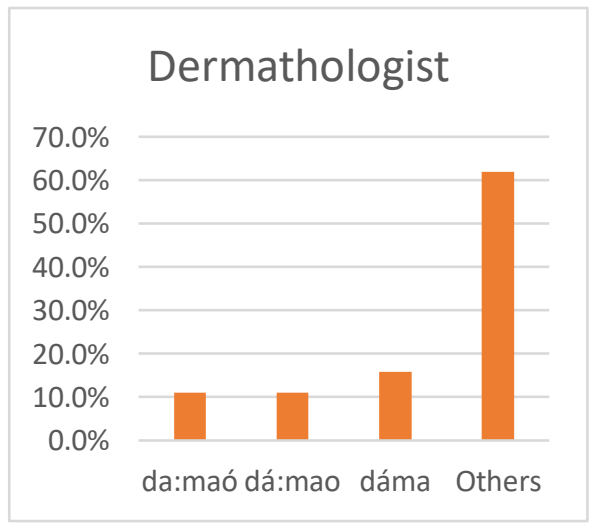


(7)

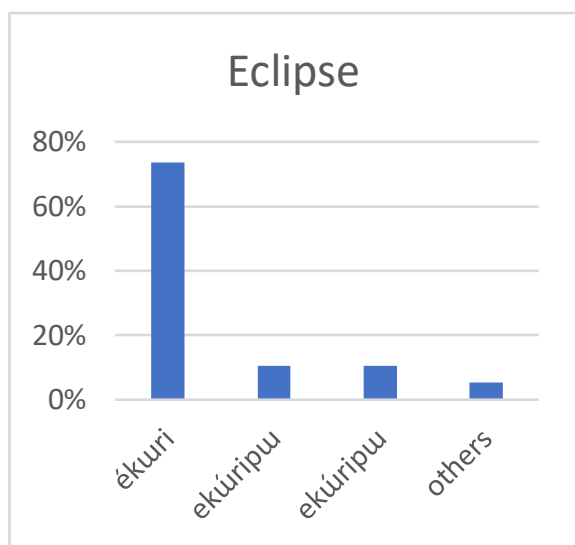

(9)

(10)

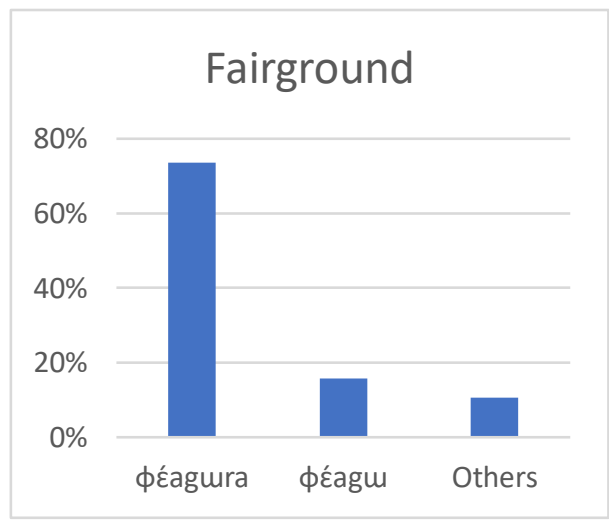

(11)

(12)

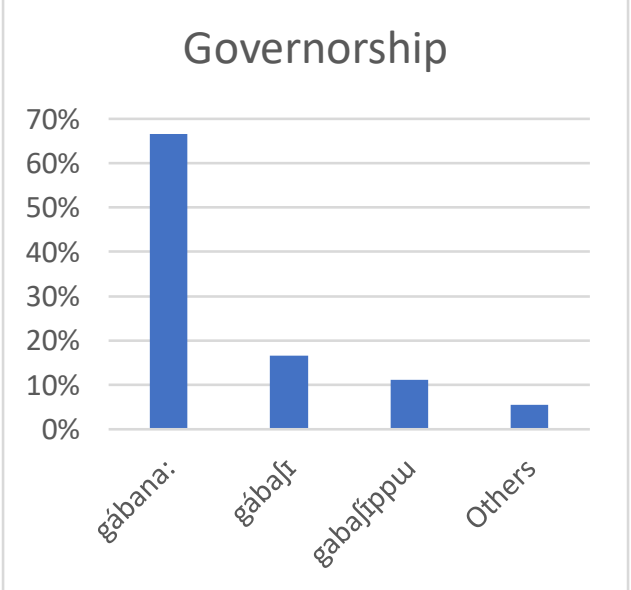

(8)
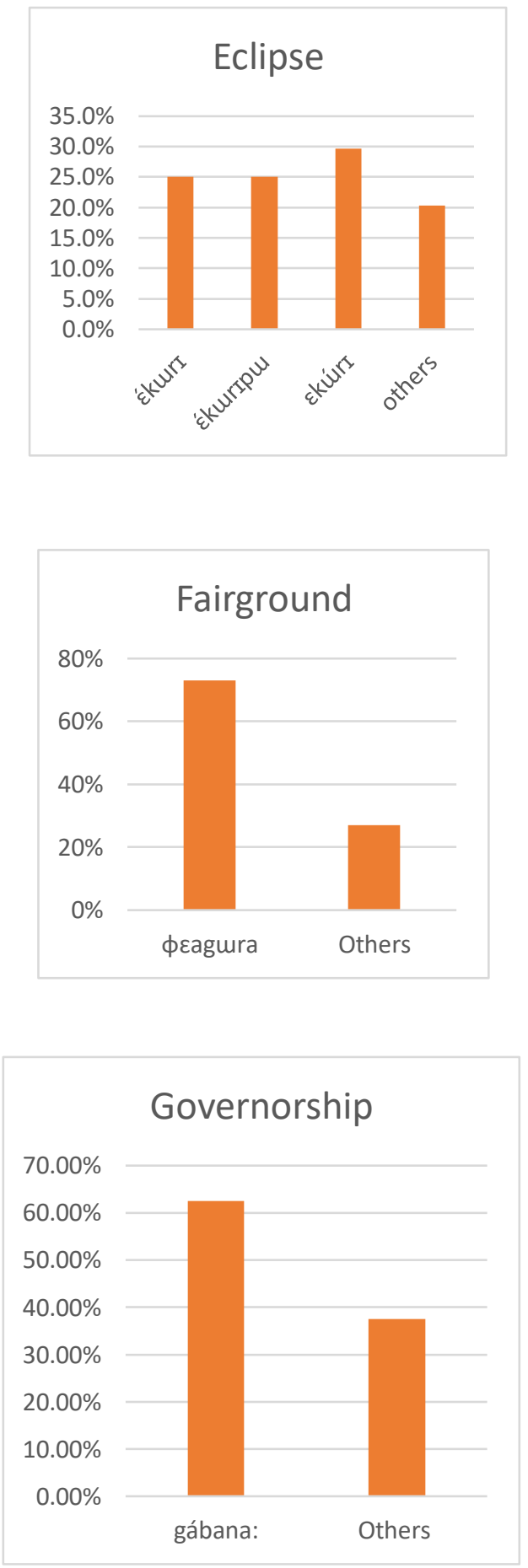
(13)

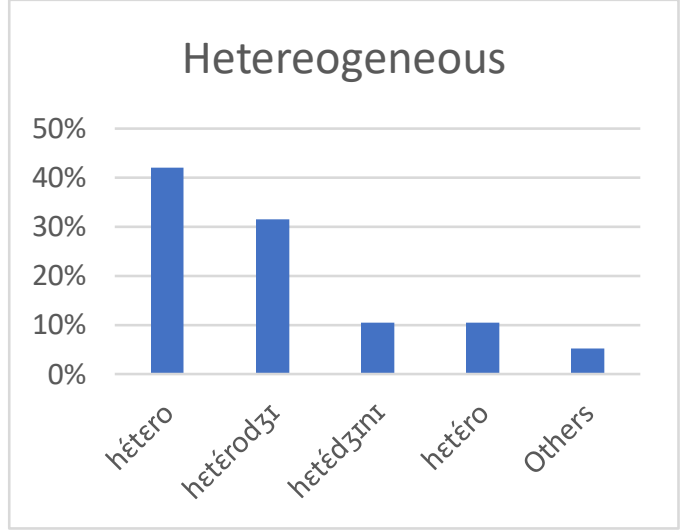

(15)

(16)

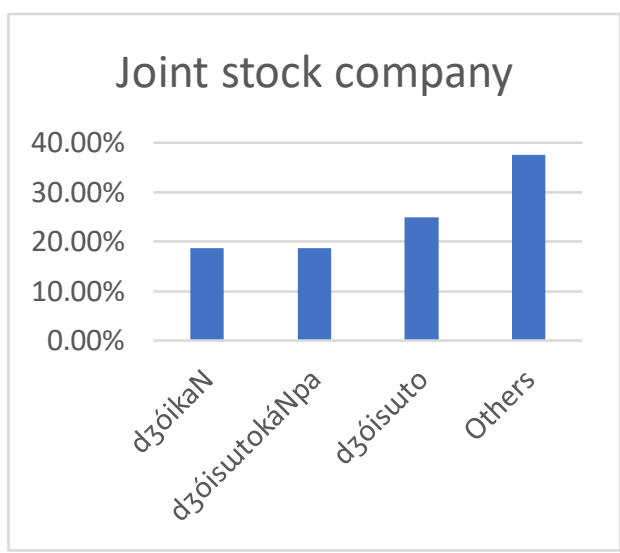

(17)

(18)

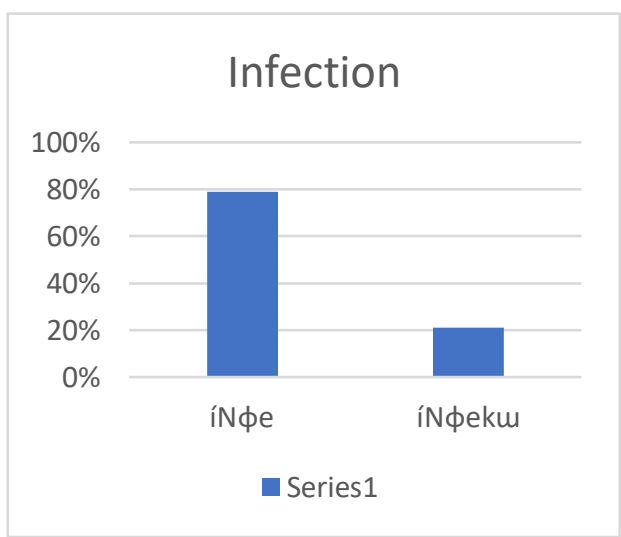

(14)
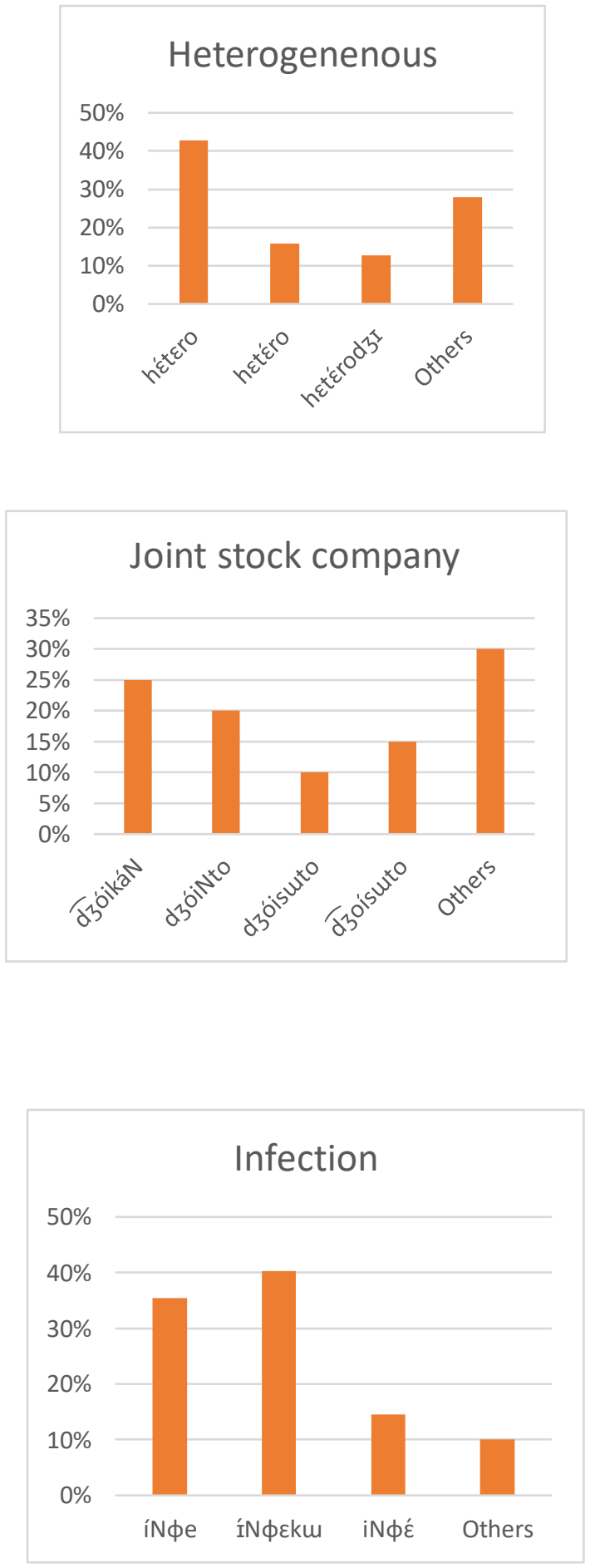
(19)

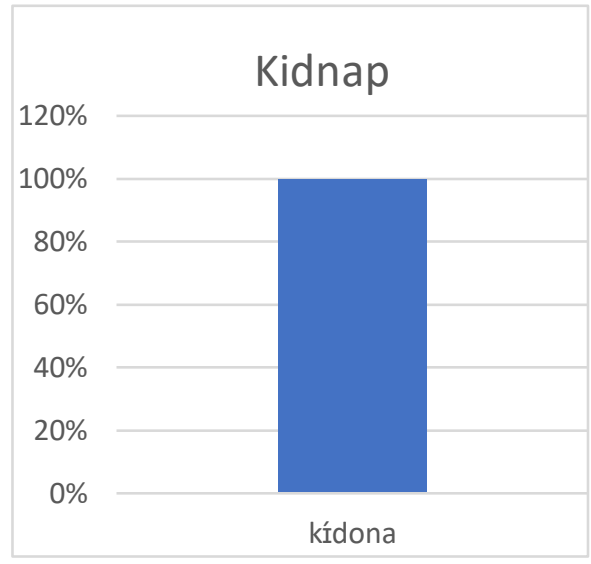

(21)

(22)

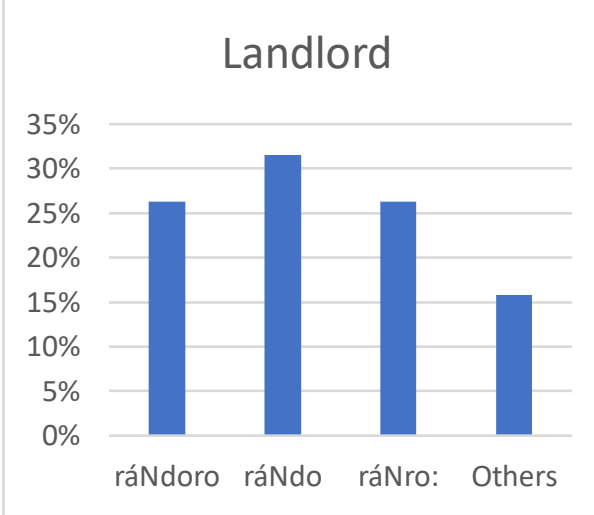

(23)

(24)

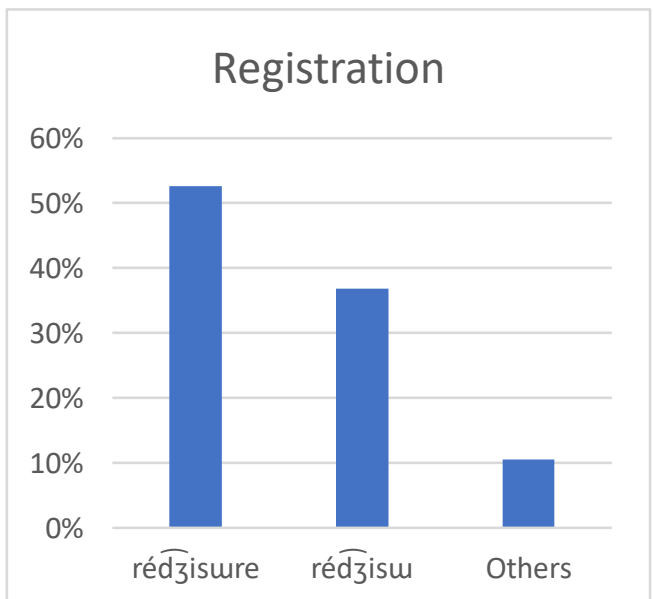

(20)
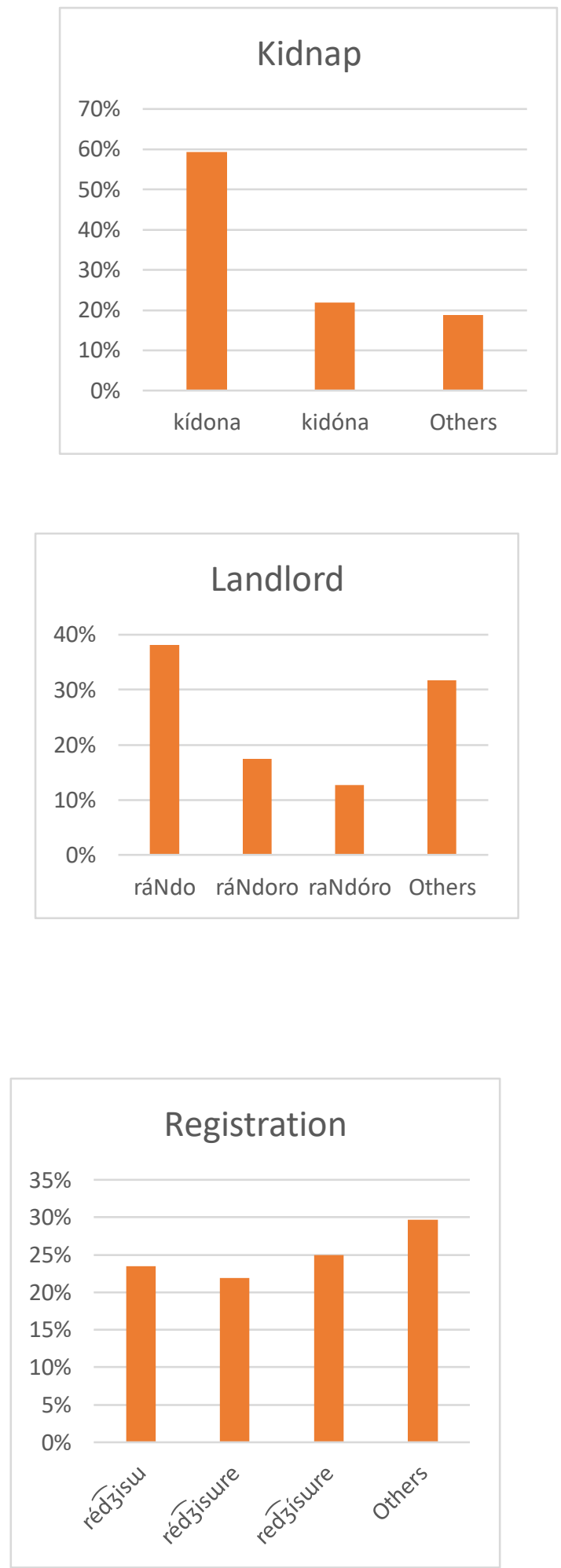
(25)

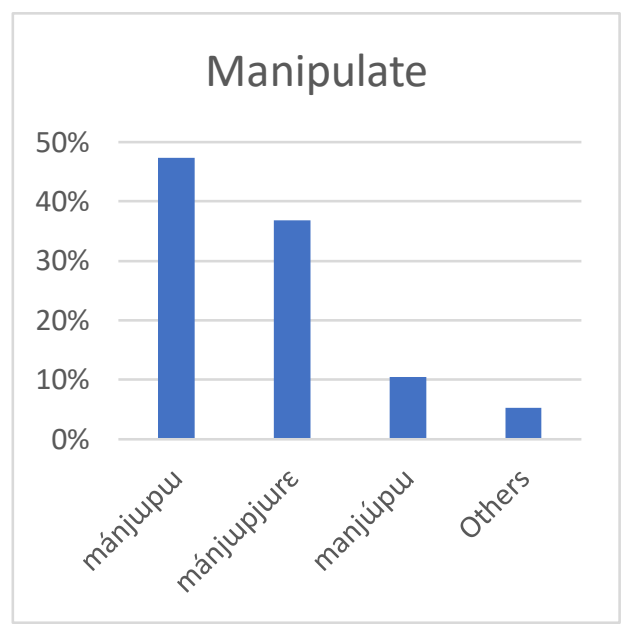

(27)

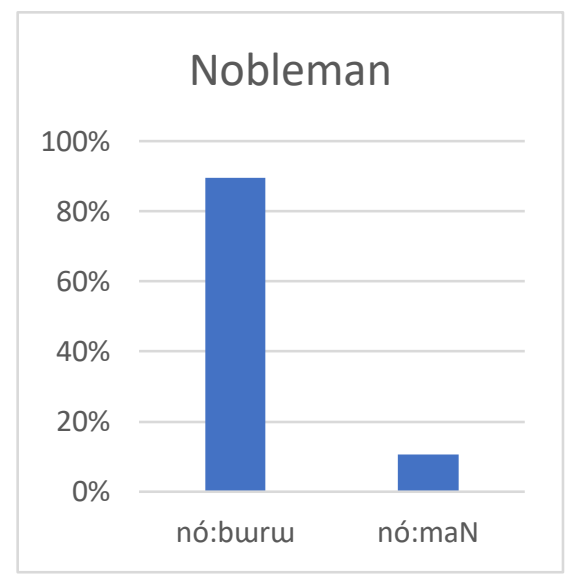

(29)

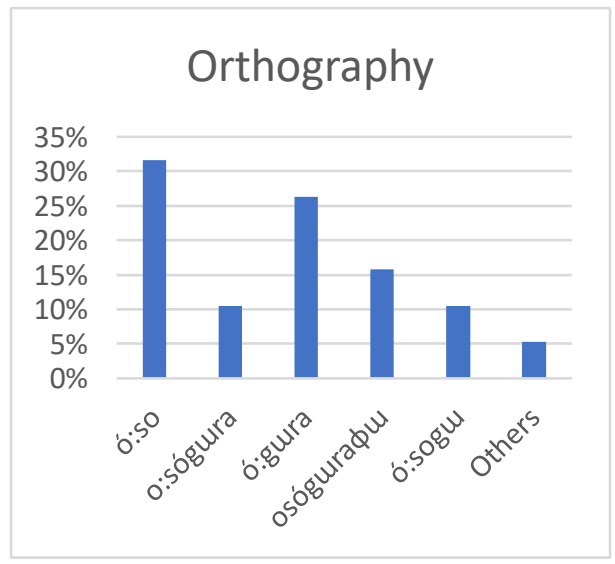

(26)

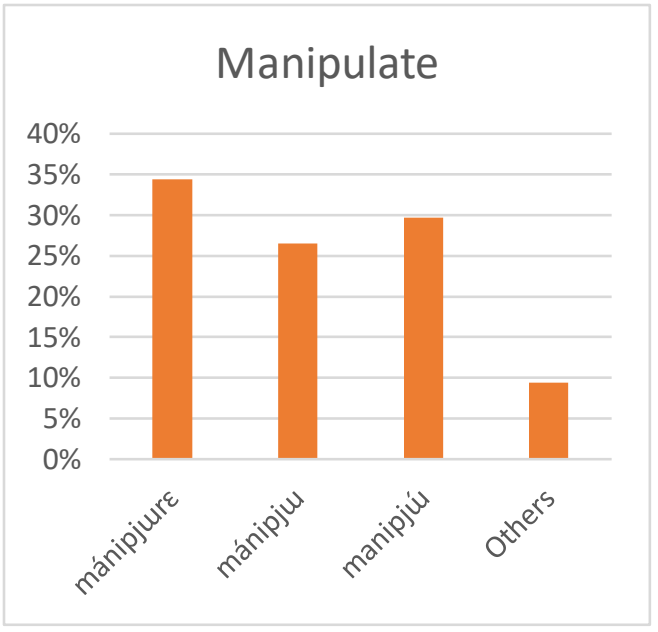

(28)

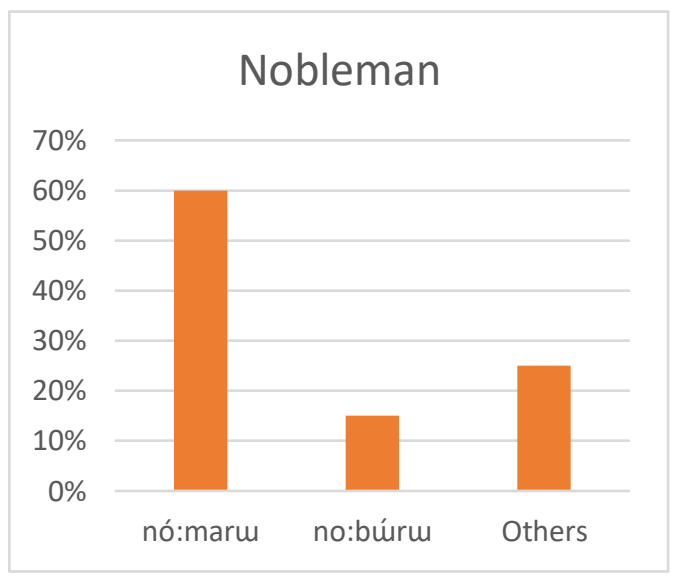

(30)

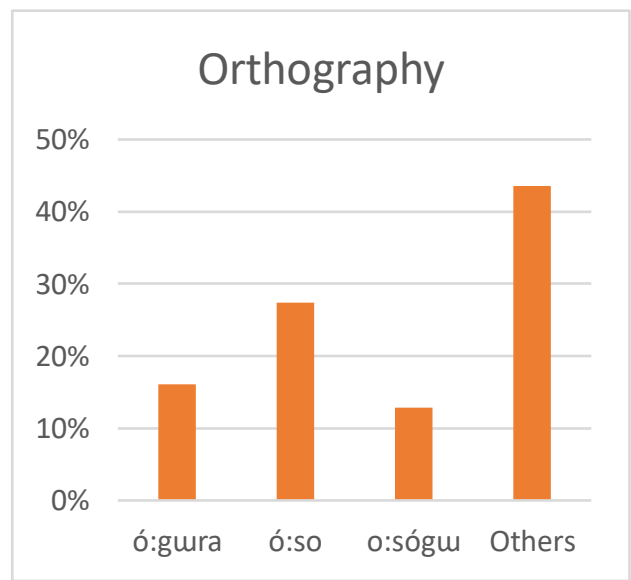


(31)

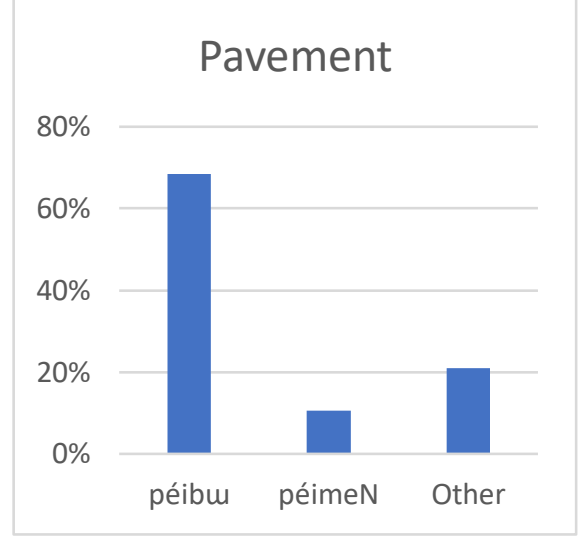

(33)

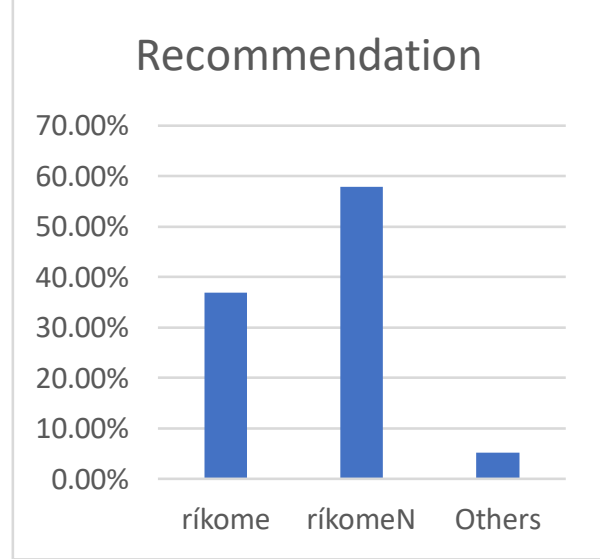

(35)

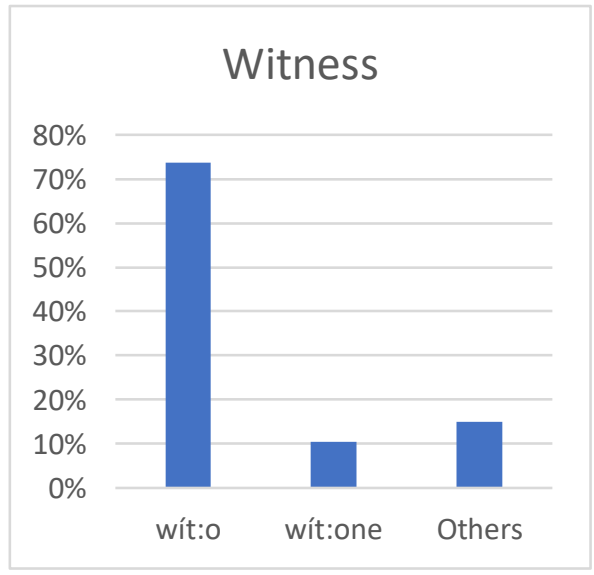

(32)

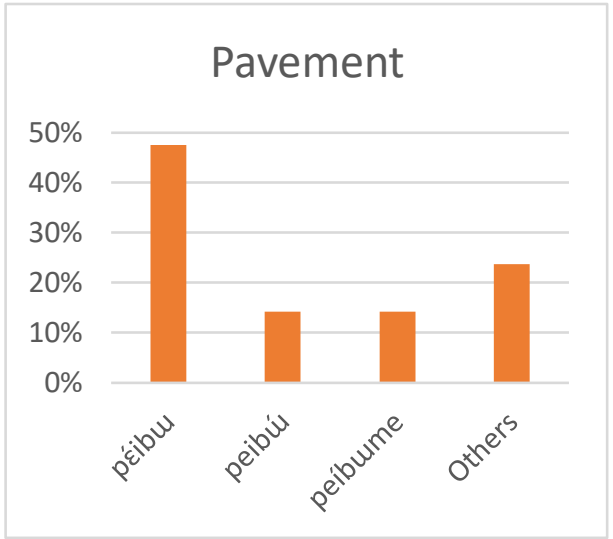

(34)

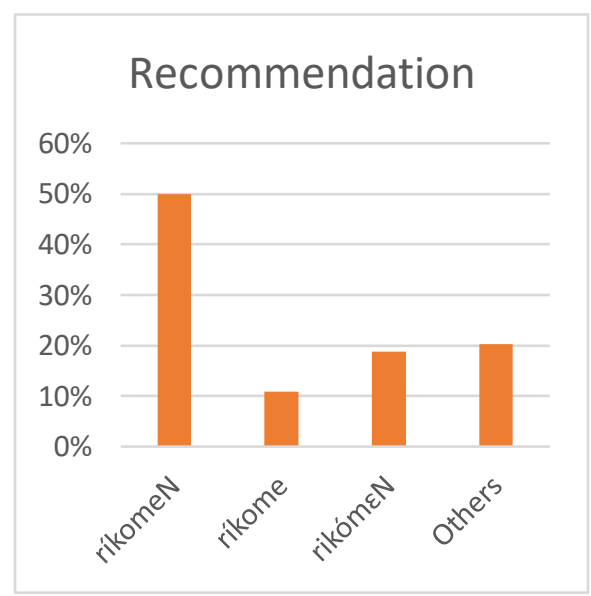

(36)

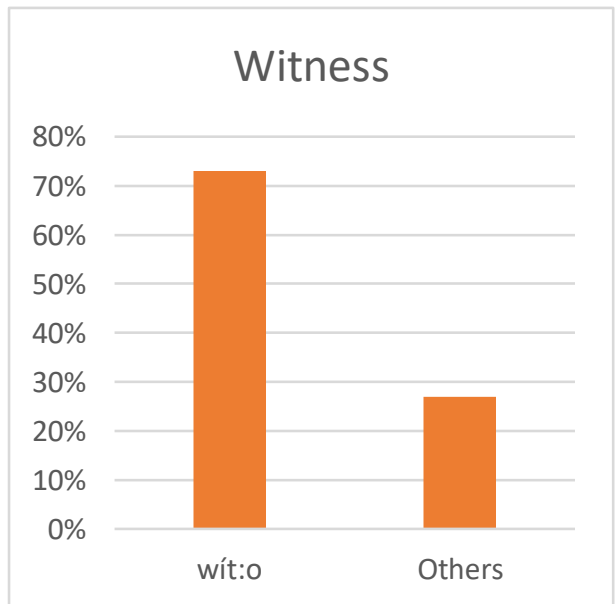



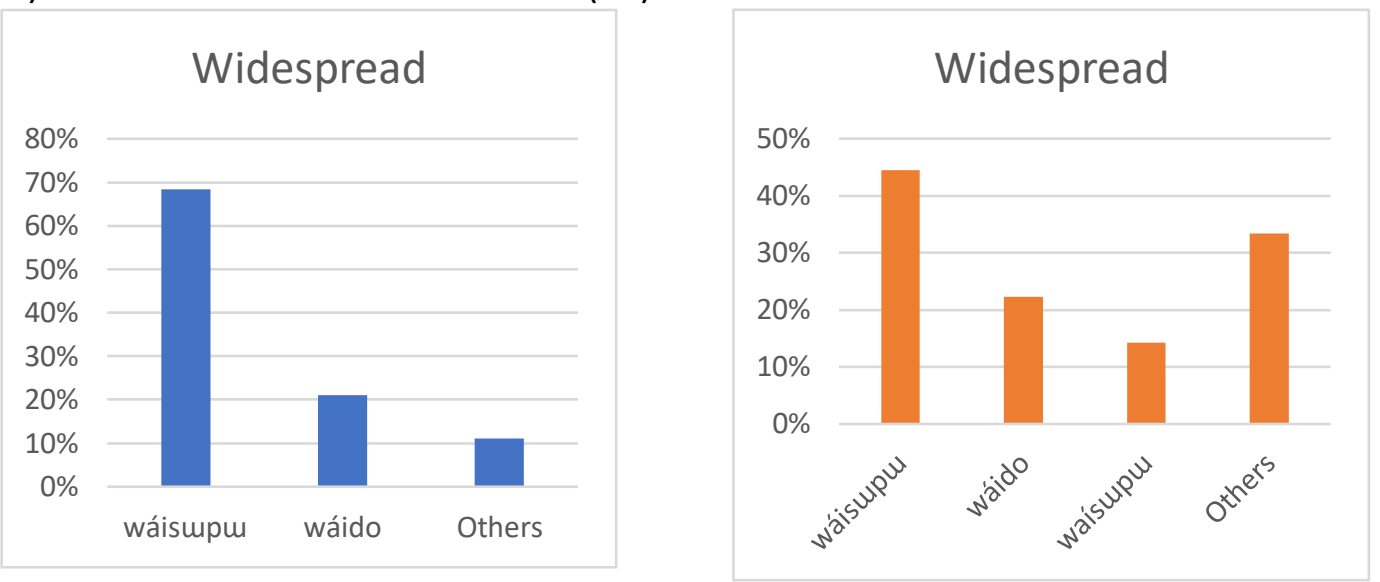

(39)

(40)
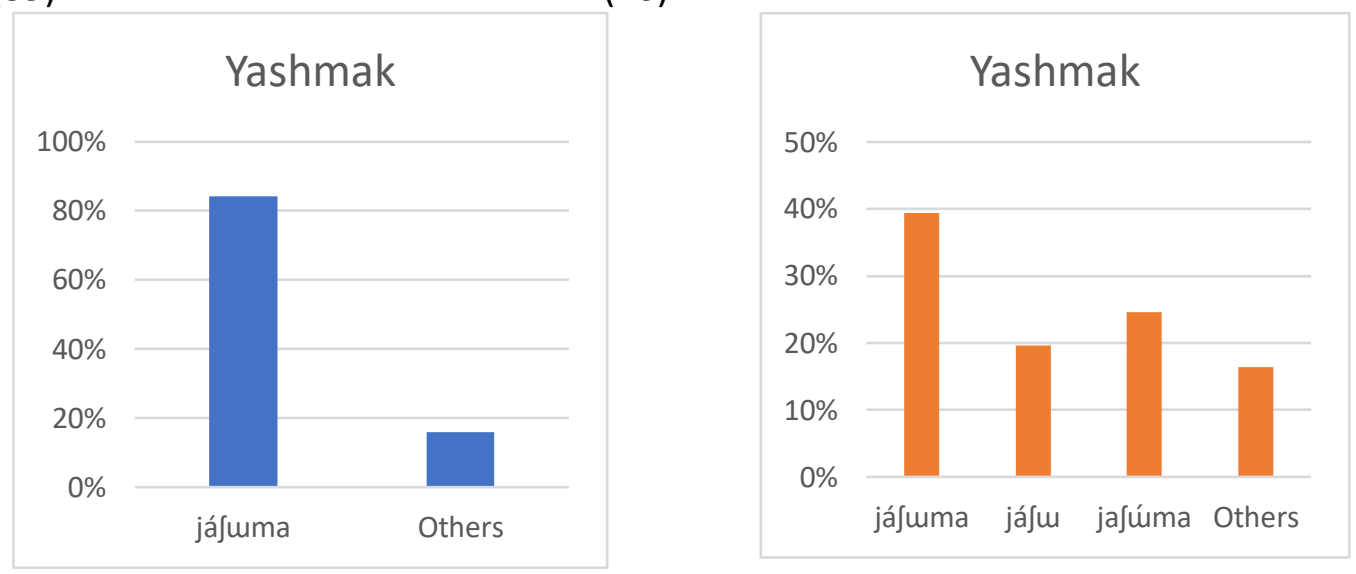

(41)

(42)
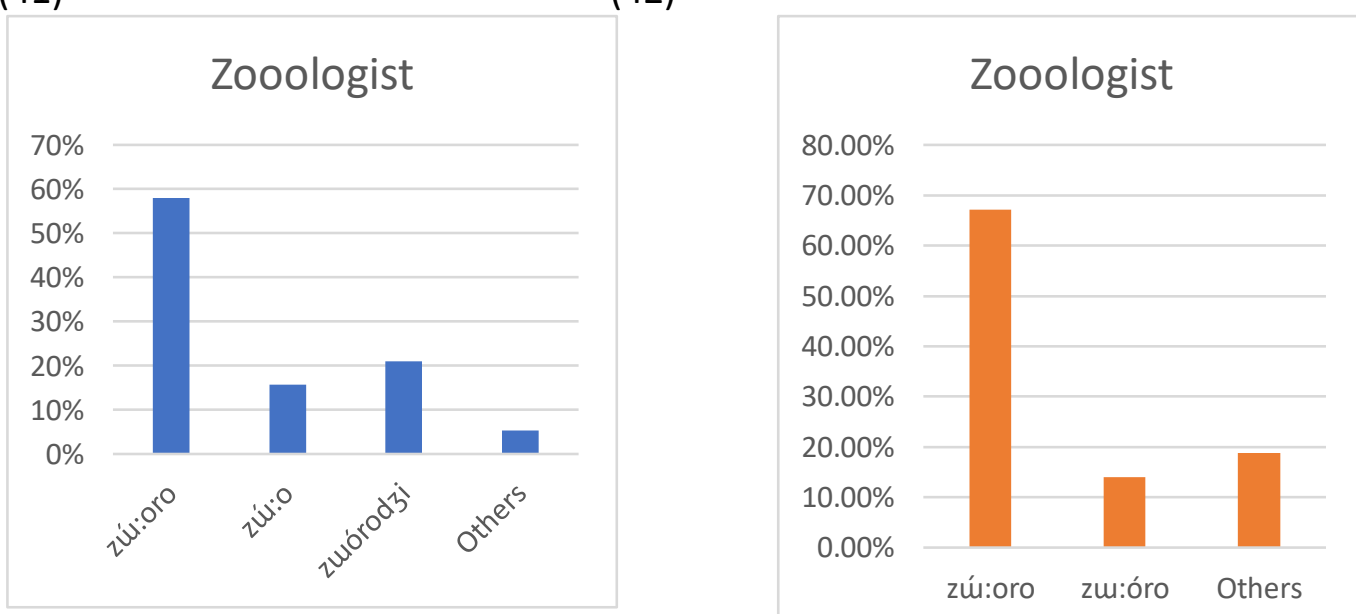
(43)

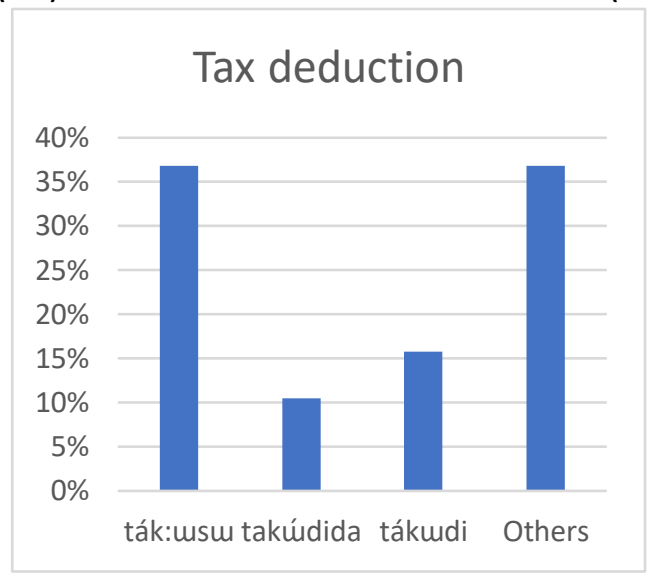

(43)

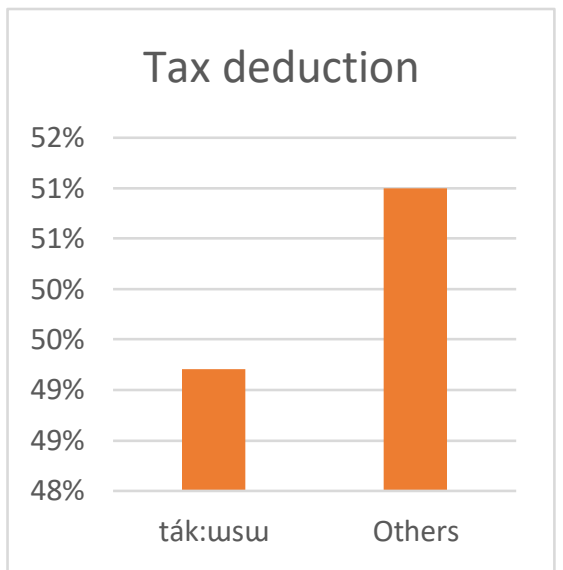

\section{Additional Questionnaire}

- When you adopt loanwords into Japanese, do you think any differences would occur between Kansai and Tokyo speech? If so, what types of differences can be seen?

- Where do you usually learn abbreviations?

- Do you think abbreviations are convenient? Why? 